\title{
A web-based collection of genotype- phenotype associations in hereditary recurrent fevers from the Eurofever registry
}

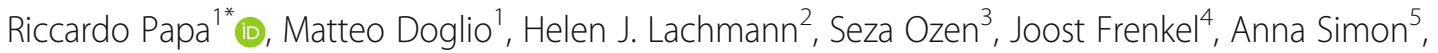
Bénédicte Neven ${ }^{6}$, Jasmin Kuemmerle-Deschner ${ }^{7}$, Huri Ozgodan ${ }^{8}$, Roberta Caorsi ${ }^{1}$, Silvia Federici ${ }^{1}$, Martina Finetti ${ }^{1}$, Maria Trachana ${ }^{9}$, Jurgen Brunner ${ }^{10}$, Liliana Bezrodnik ${ }^{11}$, Mari Carmen Pinedo Gago ${ }^{12}$, Maria Cristina Maggio ${ }^{13}$, Elena Tsitsami ${ }^{14}$, Wafaa Al Suwairi ${ }^{15}$, Graciela Espada ${ }^{16}$, Anna Shcherbina ${ }^{17}$, Guzide Aksu ${ }^{18}$, Nicolino Ruperto ${ }^{1}$, Alberto Martini ${ }^{19}$, Isabella Ceccherini ${ }^{20}$, Marco Gattorno ${ }^{1}$ and for the Paediatric Rheumatology International Trials Organisation (PRINTO) and the Eurofever Project

\begin{abstract}
Background: Hereditary recurrent fevers (HRF) are a group of rare monogenic diseases leading to recurrent inflammatory flares. A large number of variants has been described for the four genes associated with the best known HRF, namely MEFV, NLRP3, MVK, TNFRSF1A. The Infevers database (http://fmf.igh.cnrs.fr/ISSAID/infevers) is a large international registry collecting variants reported in these genes. However, no genotype-phenotype associations are provided, but only the clinical phenotype of the first patient(s) described for each mutation. The aim of this study is to develop a registry of genotype-phenotype associations observed in patients with HRF, enrolled and validated in the Eurofever registry.
\end{abstract}

Results: Genotype-phenotype associations observed in all the patients with HRF enrolled in the Eurofever registry were retrospectively analyzed. For autosomal dominant diseases (CAPS and TRAPS), all mutations were individually analyzed. For autosomal recessive diseases (FMF and MKD), homozygous and heterozygous combinations were described. Mean age of onset, disease course (recurrent or chronic), mean duration of fever episodes, clinical manifestations associated with fever episodes, atypical manifestations, complications and response to treatment were also studied.

Data observed in 751 patients (346 FMF, 133 CAPS, 114 MKD, 158 TRAPS) included in the Eurofever registry and validated by experts were summarized in Tables. A total of 149 variants were described: 46 TNFRSF1A and 27 NLRP3 variants, as well as various combinations of 48 MVK and 28 MEFV variants were available.

Conclusions: We provide a potentially useful tool for physicians dealing with HRF, namely a registry of genotypephenotype associations for patients enrolled in the Eurofever registry. This tool is complementary to the Infevers database and will be available at the Eurofever and Infevers websites.

Keywords: Hereditary recurrent fevers, FMF, Caps, Traps, MKD, Infevers, Eurofever, Genotype-phenotype associations

\footnotetext{
* Correspondence: papariccardo86@gmail.com

${ }^{1}$ EULAR Centre of Excellence in Rheumatology 2008-2018, IRCCS Istituto

Giannina Gaslini, Genoa, Italy

Full list of author information is available at the end of the article
}

(c) The Author(s). 2017 Open Access This article is distributed under the terms of the Creative Commons Attribution 4.0 International License (http://creativecommons.org/licenses/by/4.0/), which permits unrestricted use, distribution, and reproduction in any medium, provided you give appropriate credit to the original author(s) and the source, provide a link to the Creative Commons license, and indicate if changes were made. The Creative Commons Public Domain Dedication waiver (http://creativecommons.org/publicdomain/zero/1.0/) applies to the data made available in this article, unless otherwise stated. 


\section{Background}

Hereditary recurrent fevers (HRF) are a group of autoinflammatory diseases characterized by recurrent fever episodes of variable duration, associated with elevation of acute phase reactants and a number of systemic inflammatory manifestations, mainly involving skin, joints and serosal surfaces [1]. The best known HRF are Familiar Mediterranean Fever (FMF), Cryopyrin-Associated Periodic Syndrome (CAPS), TNF-receptor associated periodic fever syndrome (TRAPS) and Mevalonate-Kinase Deficiency (MKD), caused by mutations in MEFV, NLRP3, TNFRSF1A and $M V K$ genes, respectively.

The large number of common variants or polymorphisms in these genes makes assessment of genotypephenotype association difficult. Furthermore, the possible extent of clinical manifestations associated with fever in HRF is still largely unknown and atypical symptoms may be present. The Infevers database (available at http://fmf.igh.cnrs.fr/ISSAID/infevers/) collects all the reported variants of these genes [2]. Infevers provides a concise description of the clinical picture of first patient(s) reported for each given mutation, but no further genotype-phenotype association. The Eurofever project, supported by the European Agency for Health and Consumers, aims at increasing the knowledge on autoinflammatory diseases [3]. One of the main purposes of the project was to establish an international registry collecting complete demographic, genetic and clinical data of all monogenic autoinflammatory diseases. The aim of the present study is to develop an open web-based registry of genotype-phenotype associations derived from all the patients with HRF enrolled and validated in the Eurofever registry.

\section{Methods}

All patient data were extracted from the Eurofever registry, which has been enrolling patients since November 2009. Independent ethical approval for entering patients in the registry was obtained in the participating countries, in accordance with local requirements. Detailed epidemiological, demographic, molecular and clinical data were collected anonymously. The clinical characteristics included the disease pattern (defined by either recurrent acute episodes, chronic disease or chronic with acute exacerbations), disease manifestations and response to treatment. The Eurofever steering committee has appointed a group of experienced clinicians (SÖ \& HÖ for FMF; JF \& AS for MKD; HL, MG \& PW for TRAPS; BN \& JKD for CAPS) for the diagnosis adjudication process. In brief, each adjudication committee had the task to review all anonymized demographic, clinical and genetic information available to confirm/ modify/request further information/reject the diagnosis attribution by the enrolling physician.
We created a table for each HRF describing the genotype-phenotype associations observed in all the patients enrolled in the Eurofever registry from November 2009 to November 2014 and validated by the experts. The general features of each cohort of patients have been already described in separate papers [4-7]. For autosomal dominant diseases (CAPS and TRAPS), all mutations were reported individually. For autosomal recessive diseases (FMF and MKD), homozygous and all combinations of heterozygous variants were described. As complex alleles could not be excluded, combinations presented do not imply in any case compound heterozygous conditions.

A separate table was devoted to the description of the clinical phenotype of patients with an incomplete genotype, such as heterozygous patients with autosomal recessive diseases or patients carrying low-penetrance mutations or variants/polymorphisms of uncertain pathogenic significance. In particular, according to the recent literature, we considered of unknown significance the p.E148Q and p.P369S variants of the $M E F V$ gene; the p.P46L, p.R92Q and intronic variants, exept c.193-14G > A, of the TNFRSF1A gene; the p.V198 $\mathrm{M}$ and p.Q703K of the NLRP3 gene. The p.R202Q of the MEFV gene was also included in Table 6, despite this variant is considered a common and neutral polymorphism that should not be even reported [8-14].

Patients with heterozygous mutations of the $M V K$ gene were included in the study only after the demonstration of a reduced mevalonate kinase enzyme activity in leukocytes or fibroblasts, or elevated urinary mevalonic acid excretion [15]. For each variant or genotype, the following items were shown: number of patients, mean age of onset, disease course (recurrent or chronic), mean duration and frequency of fever episodes, prevalent clinical manifestations associated with fever episodes, less common manifestations, complications and response to treatments. Less common manifestations were defined as symptoms present in less than $30 \%$ of patients carrying a given genotype.

Treatment response was defined as either complete (absence of clinical manifestations with normalization of inflammatory markers), partial (general amelioration of the clinical picture according to the judgement of the enrolling physician without a complete normalization of the clinical manifestations and/or systemic inflammation), or failure (lack of response according the judgment of the enrolling physician). The distinction between on demand and continuous treatment was also possible.

\section{Results}

A total of 751 patients (346 FMF, 114 MKD, 158 TRAPS, 133 CAPS) were enrolled in the analysis 
(Table 1). In total, 149 variants of the four genes associated with HRF are reported.

A summary of the main clinical features associated with homozygous or more than one heterozygous variants combinations of $19 \mathrm{MEFV}$ and $47 \mathrm{MVK}$ mutations are described in Tables 2 and 3. Tables 4 and 5 show the main clinical features of patients carrying 44 TNFRSF1A and 25 NLRP3 mutations, respectively. In Table 6, data of 210 patients with an incomplete or not confirmatory genotype are also reported. In case of autosomal recessive diseases, we reported as first mutation the variant nearest to the proximal end of the coding sequence.

Among 346 FMF patients, 238 were collected in the Table 2, 112 of which were homozygous and 126 carried more than one heterozygous variant. Unfortunately, in these cases, as we did not know the phasing of the alleles, no confirmatory genotype could be assessed. The most frequent mutations are p.M694 V (192 patients), p.V726A (48), p.M680IGC (43), and p.E148Q (31). One hundred eight patients were classified as FMF despite an incomplete (heterozygous) or not confirmatory (p.R202Q or variants of unknown significance) genotype. The clinical features of these patients are reported in Table 6.

Forty-six variants were reported in 158 TRAPS patients. Of these, 4 variants are in intronic regions, 18 involved cysteine domains and 3 are deletions. The most frequent mutations are p.T50 M (16 patients) and p.C33Y (12). The clinical characteristics of 62 patients carrying variants of unknown significance, namely p.R92Q (53) and p.P46L (5), or intronic variants (4), exept c.193-14G > A, are reported in Table 6.

Among the 133 CAPS patients analyzed, 27 different variants were reported in Table 3 . With the exception of the variant p.L1016F, that is located in exon 9, all the other variants are on exon 3 . The most frequent variants are p.R260W (32 patients) and p.T348 M (21). The patients carrying variants of unknown significance, namely p.V198 M and p.Q703K, are reported in Table 6.

Finally, 114 MKD patients were reported. Seventeen patients were homozygous and 83 heterozygous for

Table 1 Demographic characteristics of the patients

\begin{tabular}{lllll}
\hline Disease & Fmf & Mkd & Traps & Caps \\
\hline$N^{\circ}$ of patients & 346 & 114 & 158 & 133 \\
N $^{\circ}$ of countries & 28 & 12 & 18 & 16 \\
N $^{\circ}$ of variants & 28 & 48 & 46 & 27 \\
N $^{\circ}$ of variants of & 2 & - & 5 & 2 \\
unknown significance & & & & - \\
N $^{\circ}$ of combinations & 33 & 50 & - & - \\
- Heterozygous & 26 & 46 & - & - \\
- Homozygous & 7 & 4 & - & $0.8(0-45)$ \\
Age at onset & $3(0-67)$ & $0.5(0-11)$ & $4.3(0-63)$ & \\
(years: median, range) & & & & \\
\hline
\end{tabular}

more than one variant, showing 47 different combinations of mutations/deletions (Table 2). The most frequent variants were p.V377I (98 patients) and p.I268T (28). Three deletions are described. The clinical features of 14 patients harbouring one MVK mutation (heterozygous) in combination with an abnormal metabolic test are reported in Table 6.

\section{Discussion}

In the present paper we report the largest collection of data related to genotype-phenotype associations of inherited recurrent fevers. The aim of the present work was to provide clinicians and geneticists, working in the field of autoinflammatory diseases, with a practical tool for the interpretation of the results coming from the genetic analysis and to verify the phenotypes already described with a given genotype.

So far, the Infevers database has been the most commonly used tool for the orientation on the clinical relevance of a given variant detected in HRF genes. Infevers is a registry of all the variants identified in association with Autoinfammatory diseases. At present 1523 variants associated with 30 autoinflammatory diseases are reported. Among them, 317 variants for $M E F V, 204$ for $M V K, 150$ for TNFRSF1A and 182 for NLRP3. For each variant a number of input datais provided (i.e. location, sequence and protein name of Human Genome Variation Society). In addition, a rough description of the clinical phenotype described in the first patient(s) in which a given variant has been identified is also provided. Due to this limitation, Infevers recommends not to use the database as a tool for genotype-phenotype associations.

A number of other web-based instruments provide information concerning the in-silico prediction of the functional impact of each known variant and its frequency in different populations (e.i. https://varsome.com/, http:// www.ensembl.org/index.html, ecc.). In some cases, references to published data concerning the clinical phenotype can be also retrieved. However, these instruments are mainly targeted to geneticists and are not of immediate use for the clinicians in the everyday clinical practice. With the present work, we would like to provide an easy instrument for the evaluation of the genotype-phenotype associations, possibly related to different variants associated with HRF.

One important caveat is that this data set only includes patients with a verified diagnosis of an inherited fever syndrome. Some of these patients carry known low penetrance variants such as p.E148Q and p.P369S in $M E F V$; p.R92Q and p.P46L in TNFRSF1A; p.V198 M and p.Q703K in NLRP3. These genetic variants are frequent in the healthy population although they are usually over represented in patients referred for 


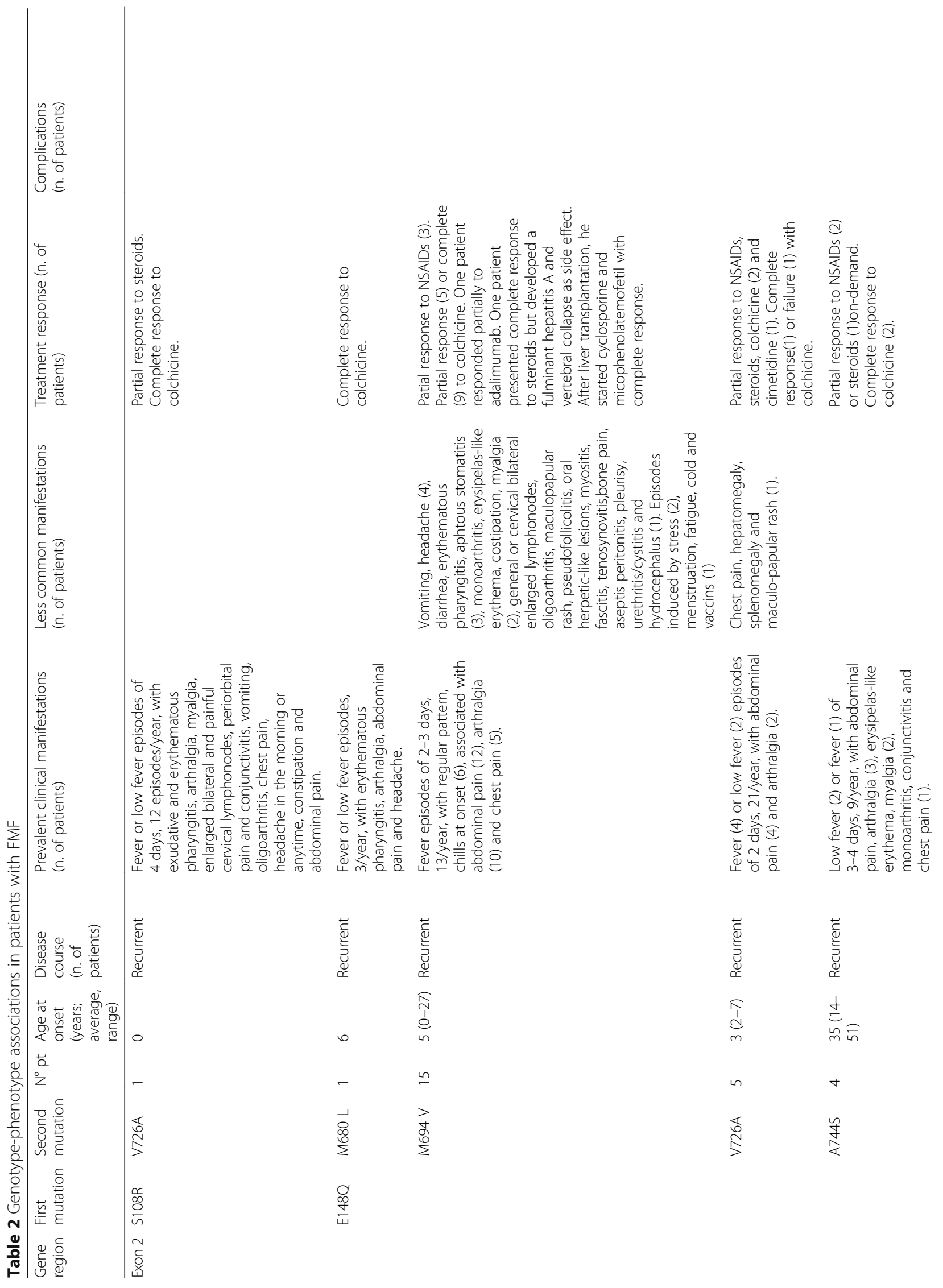




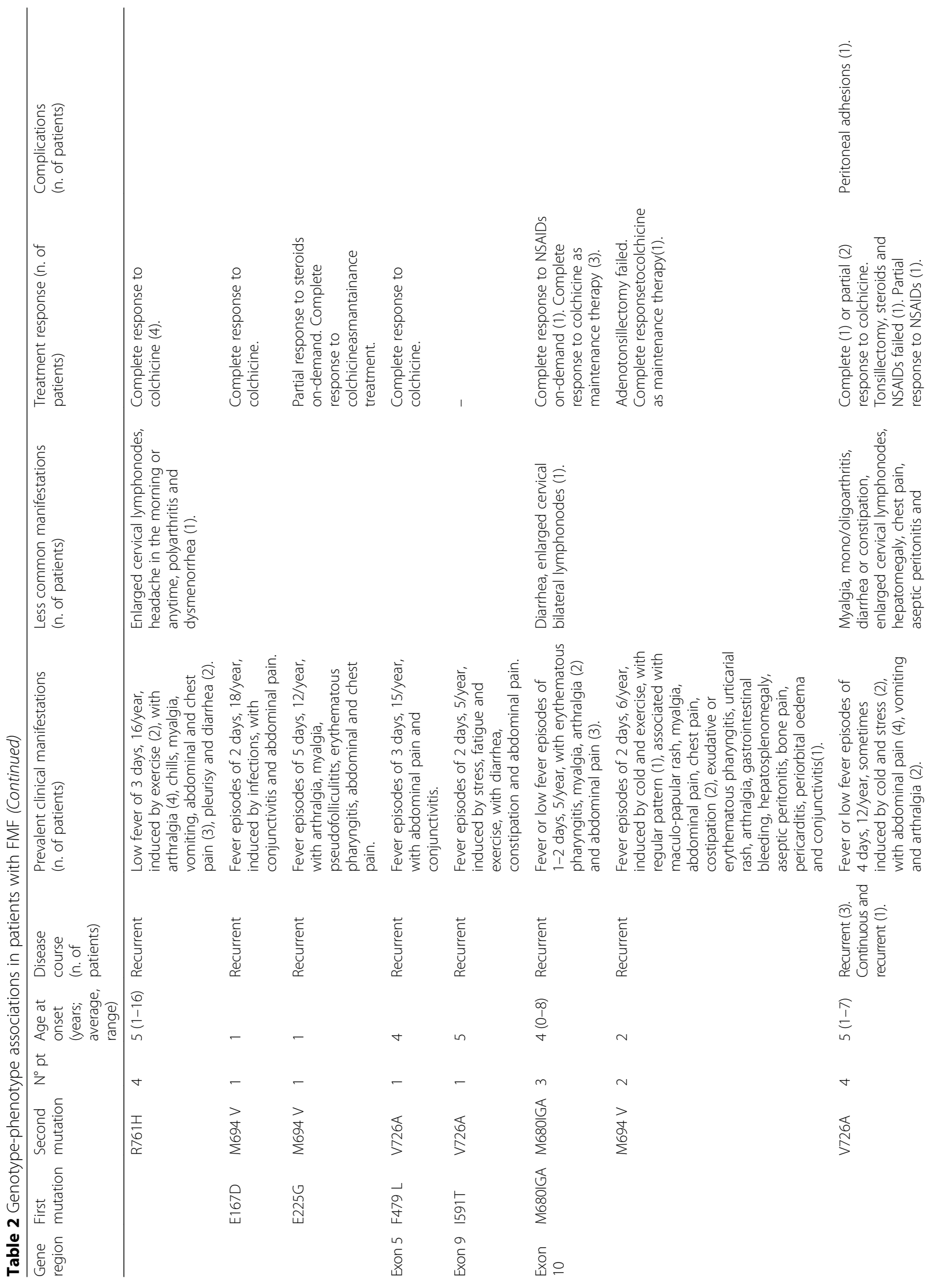




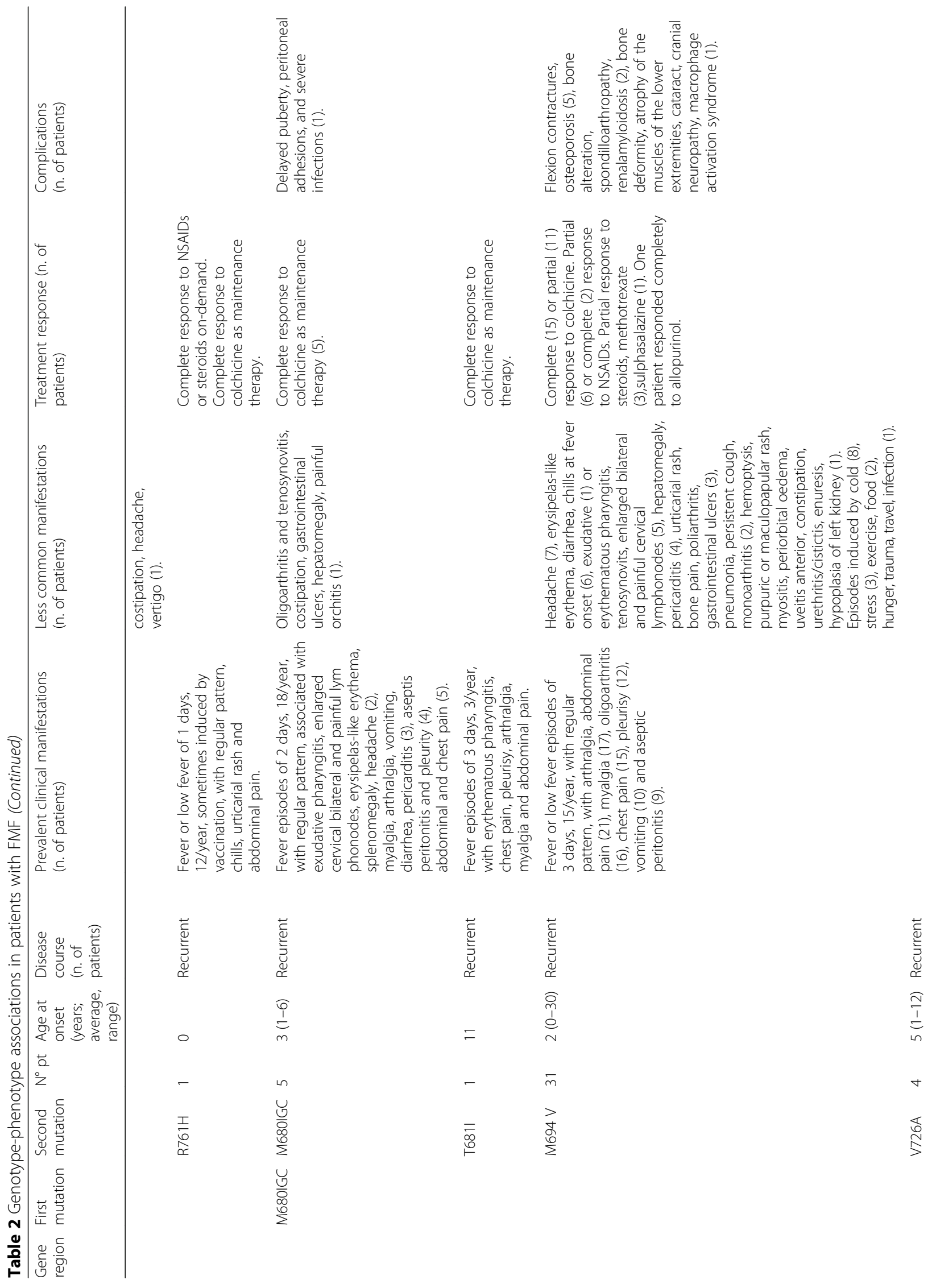




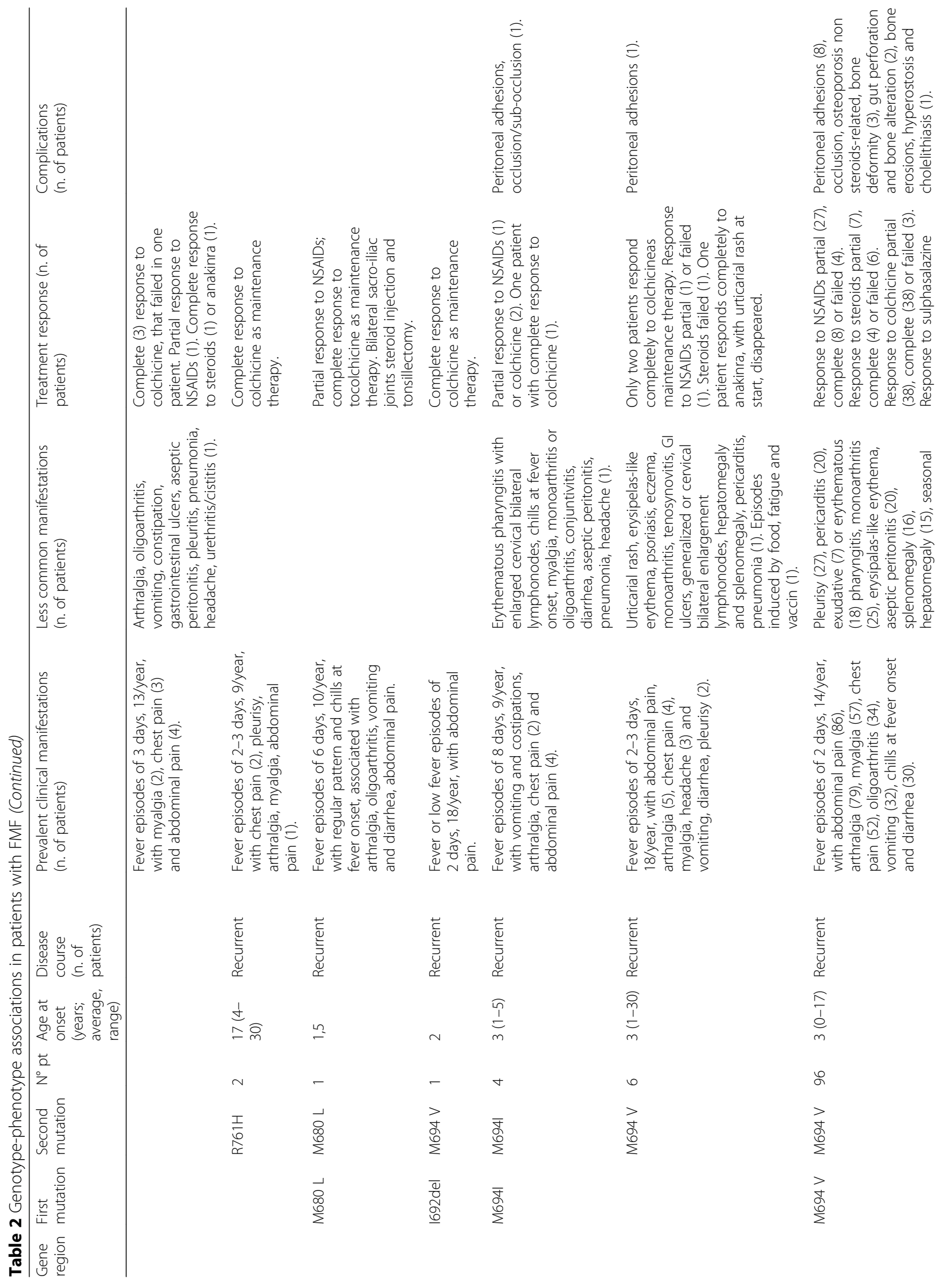




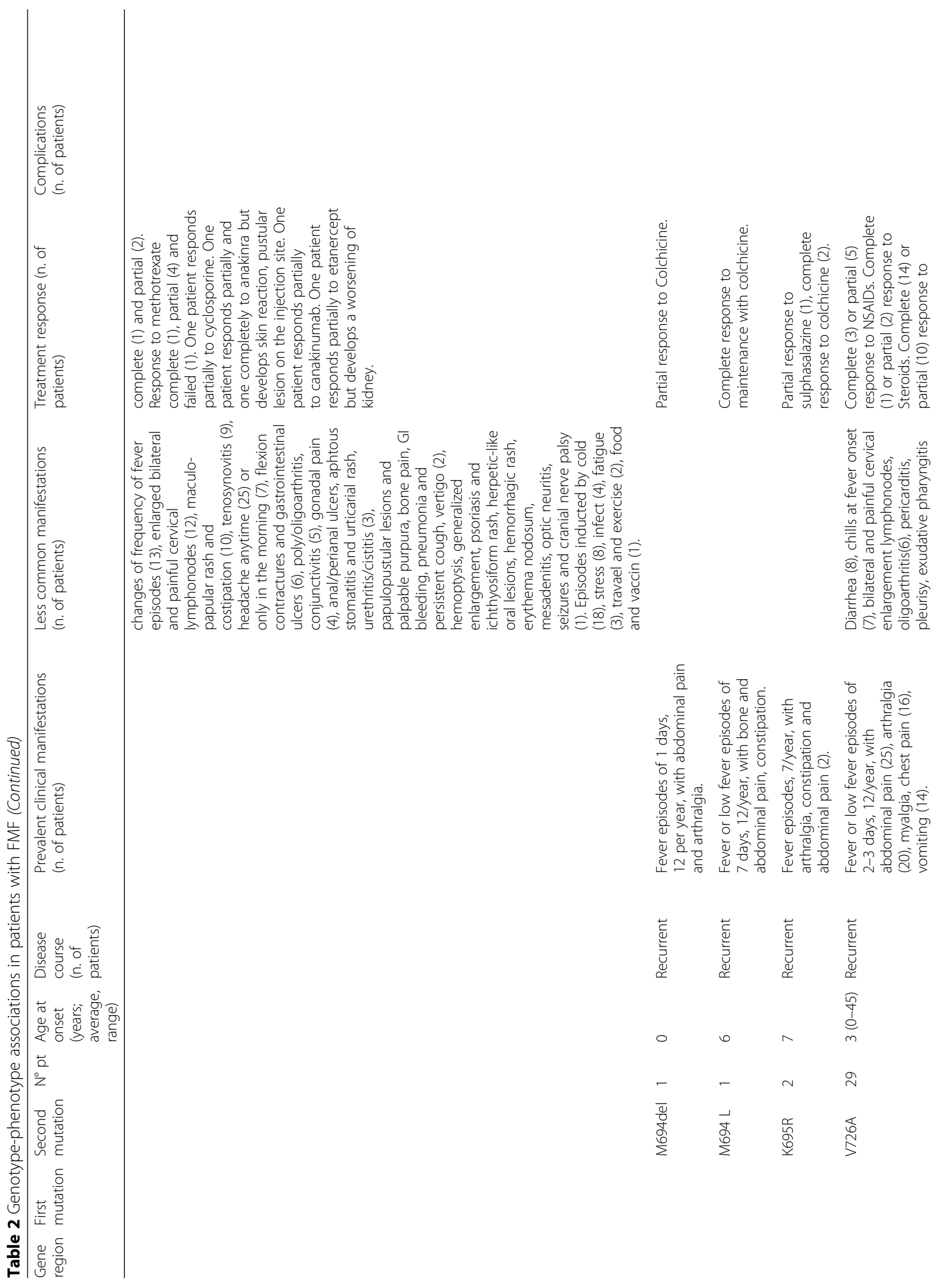




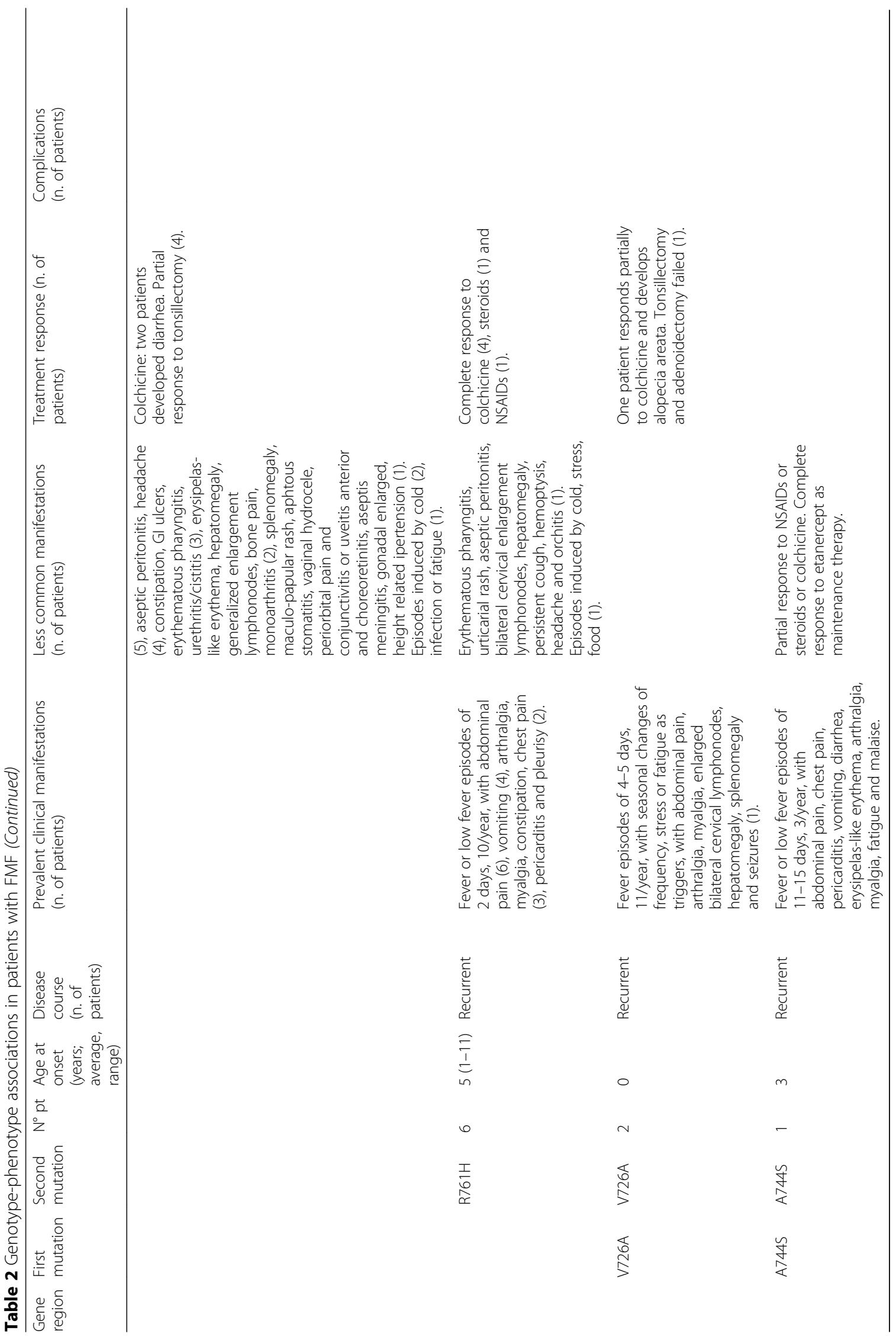




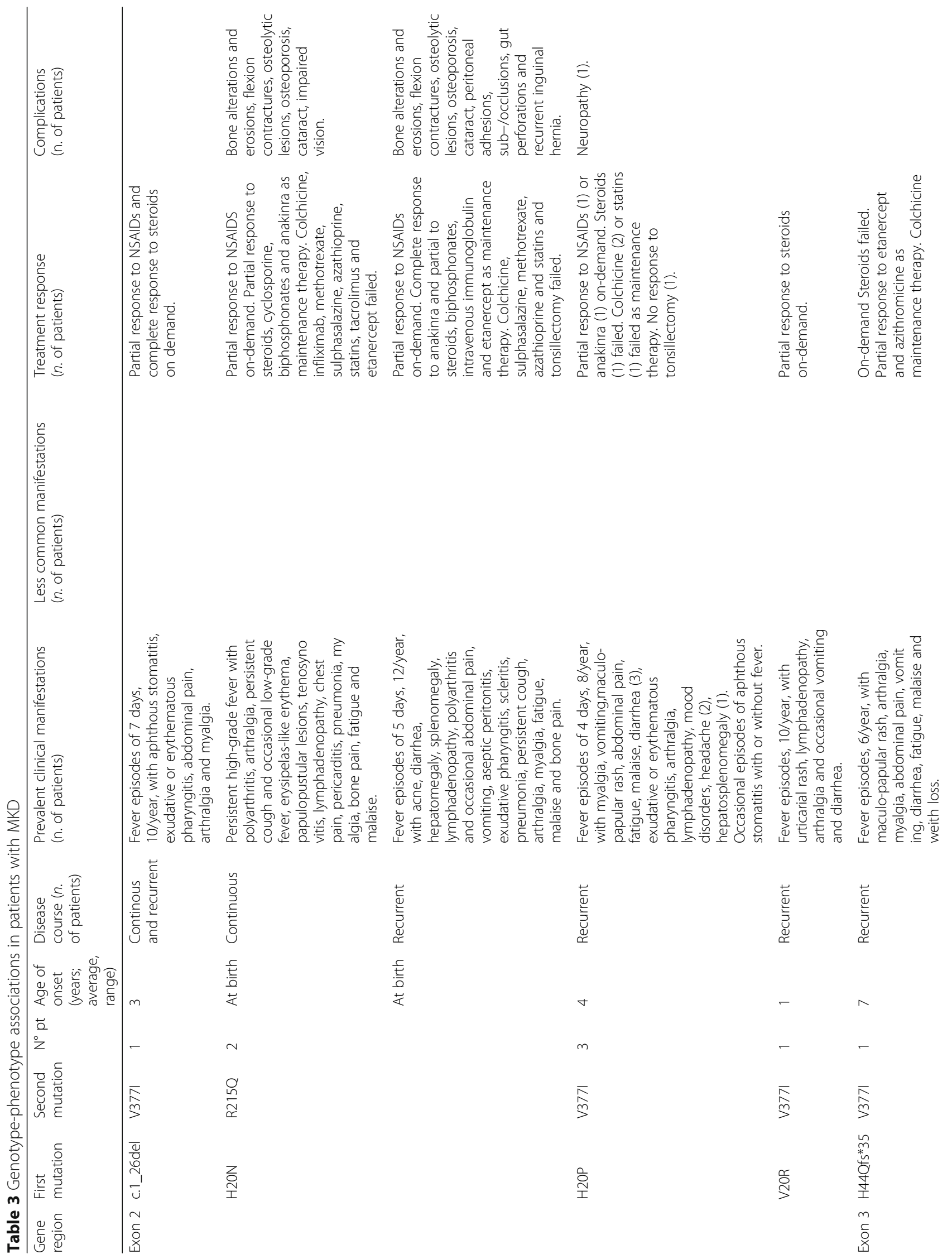




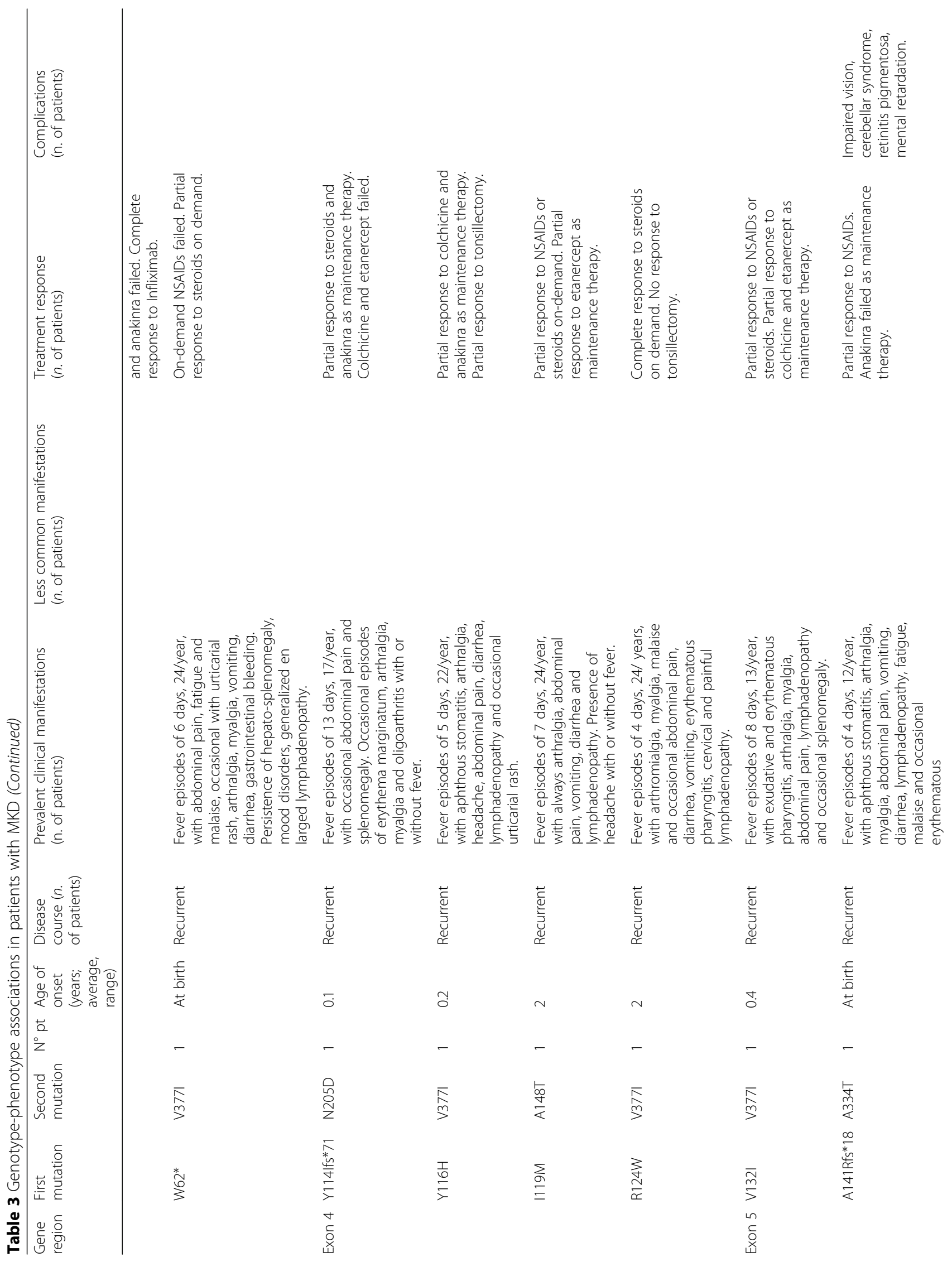




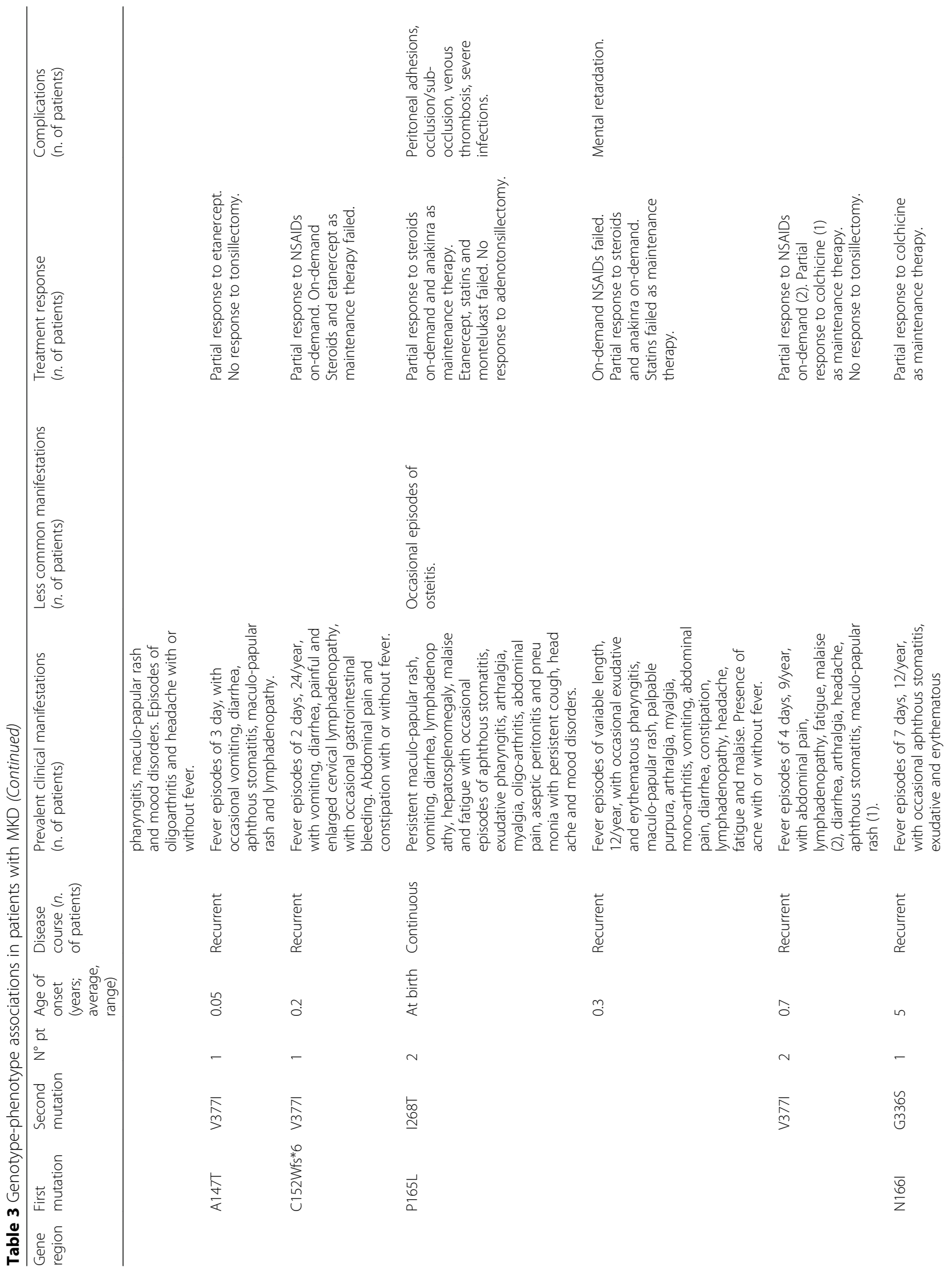




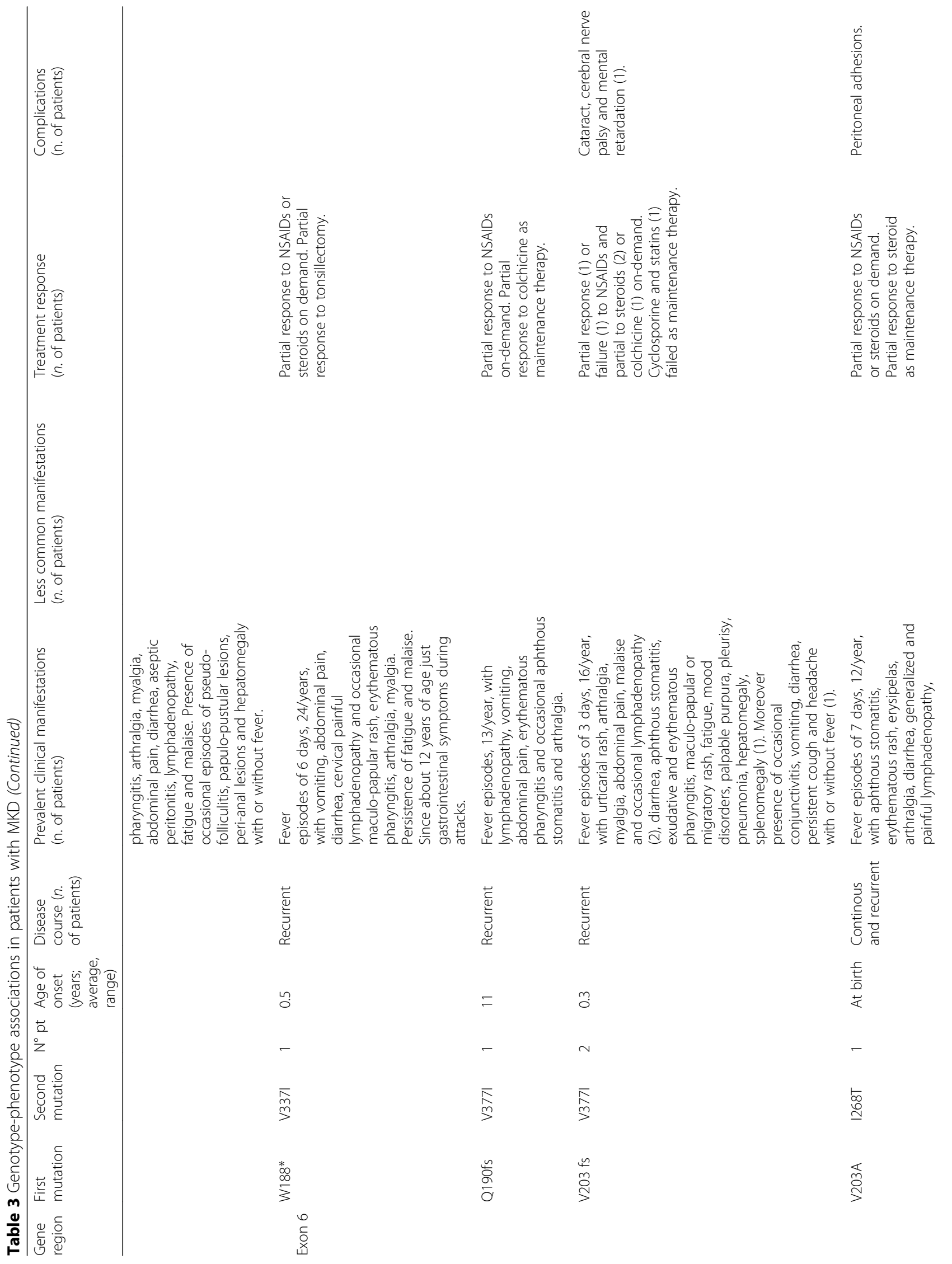




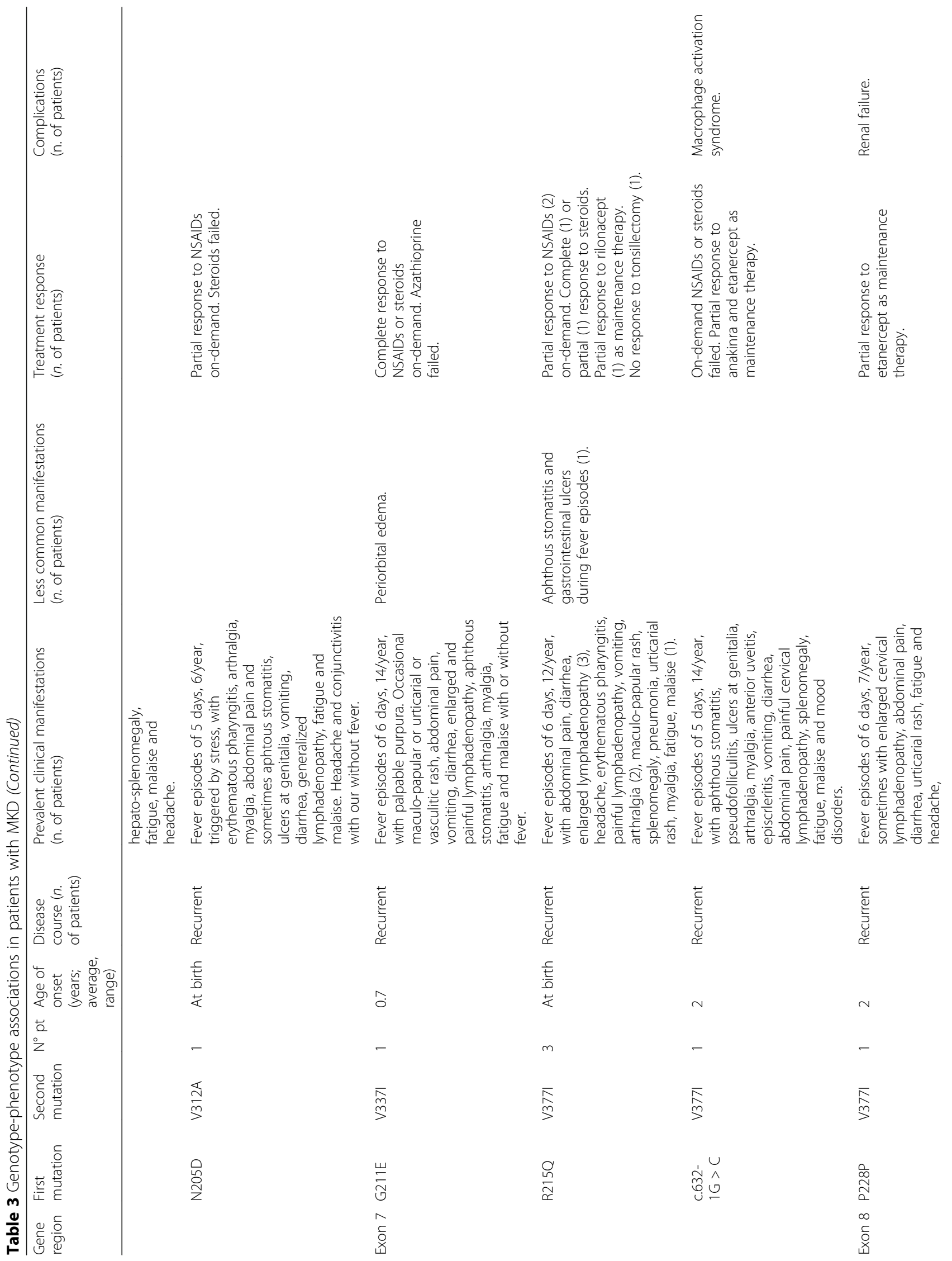




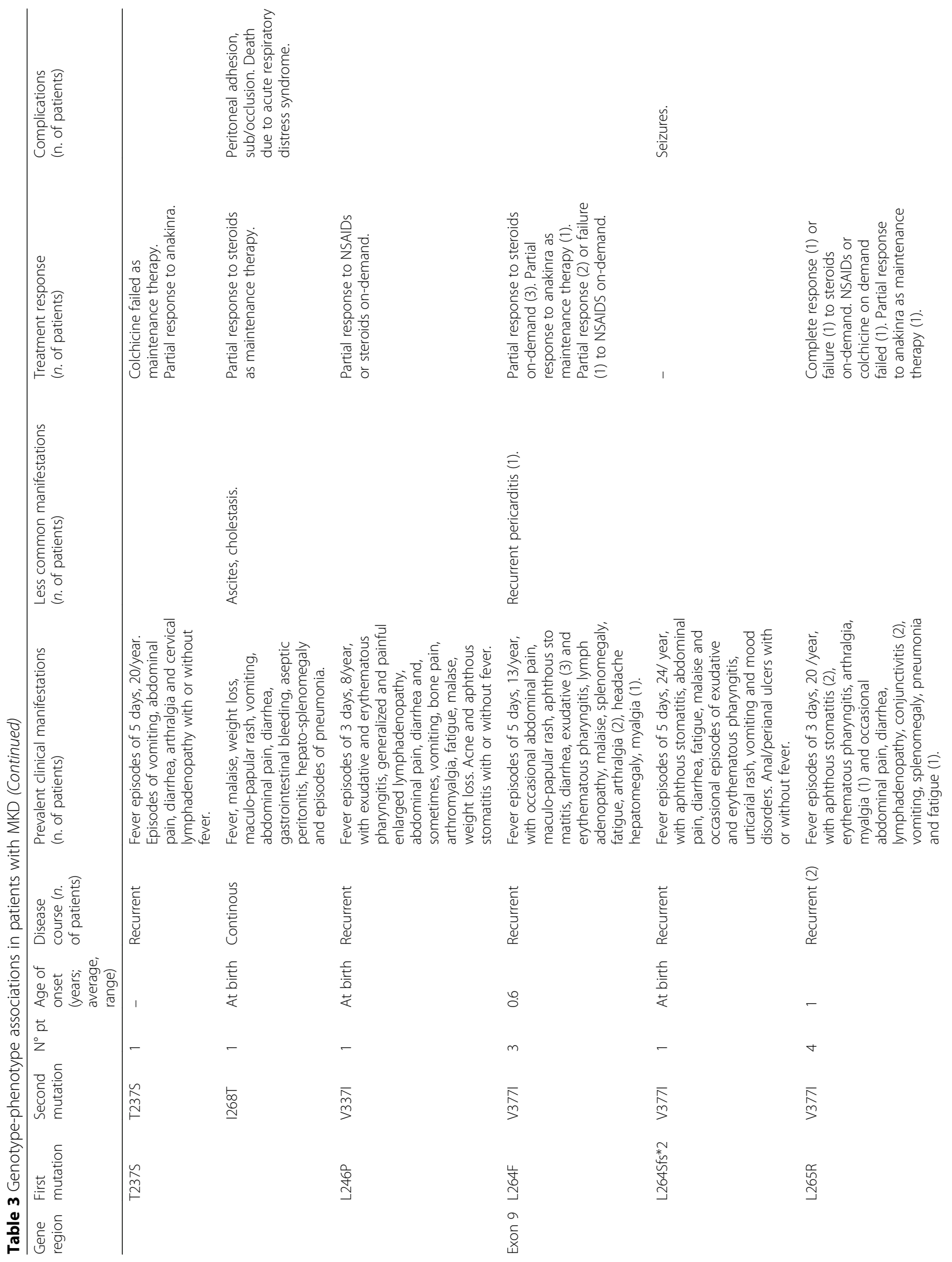




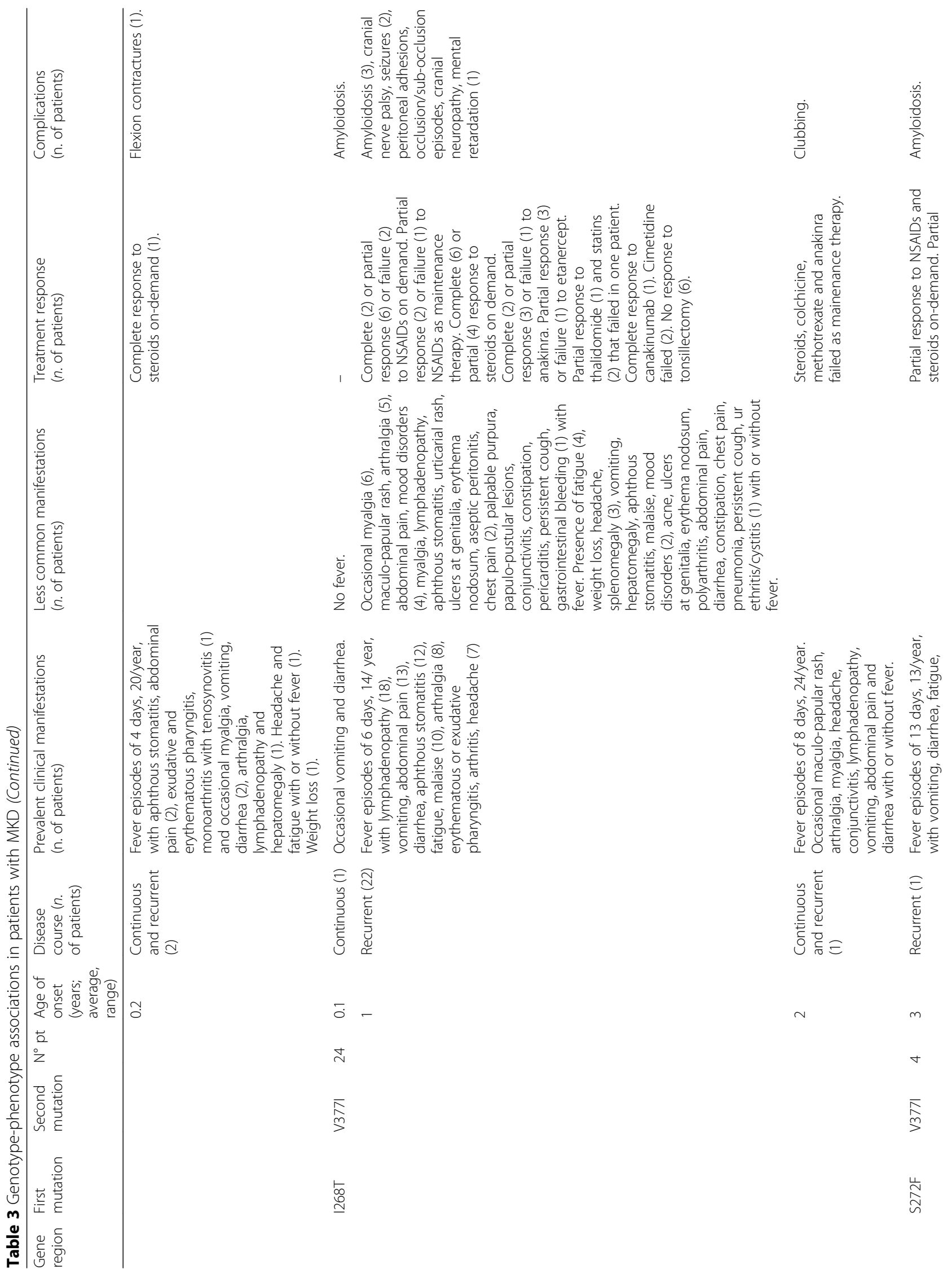




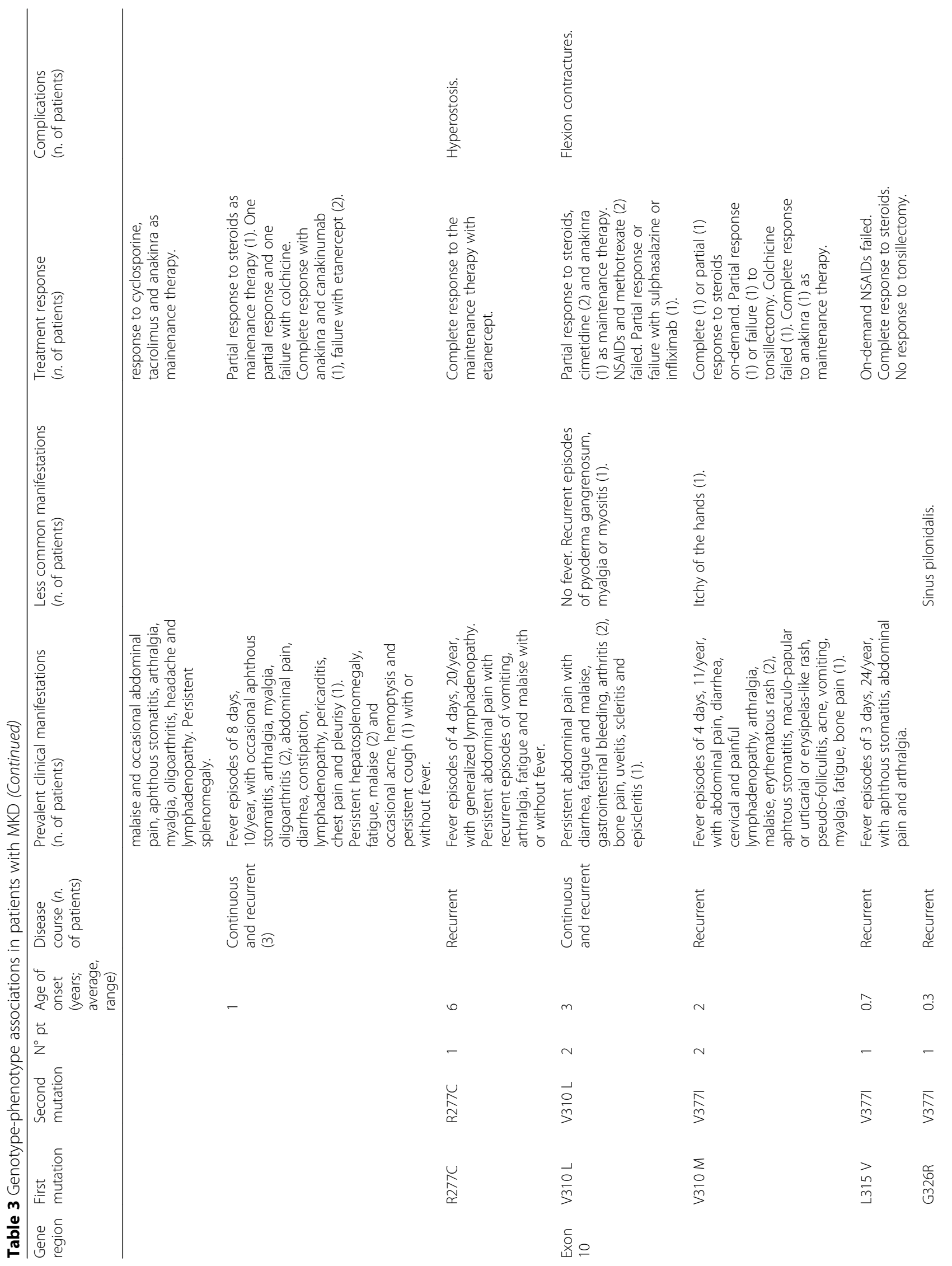




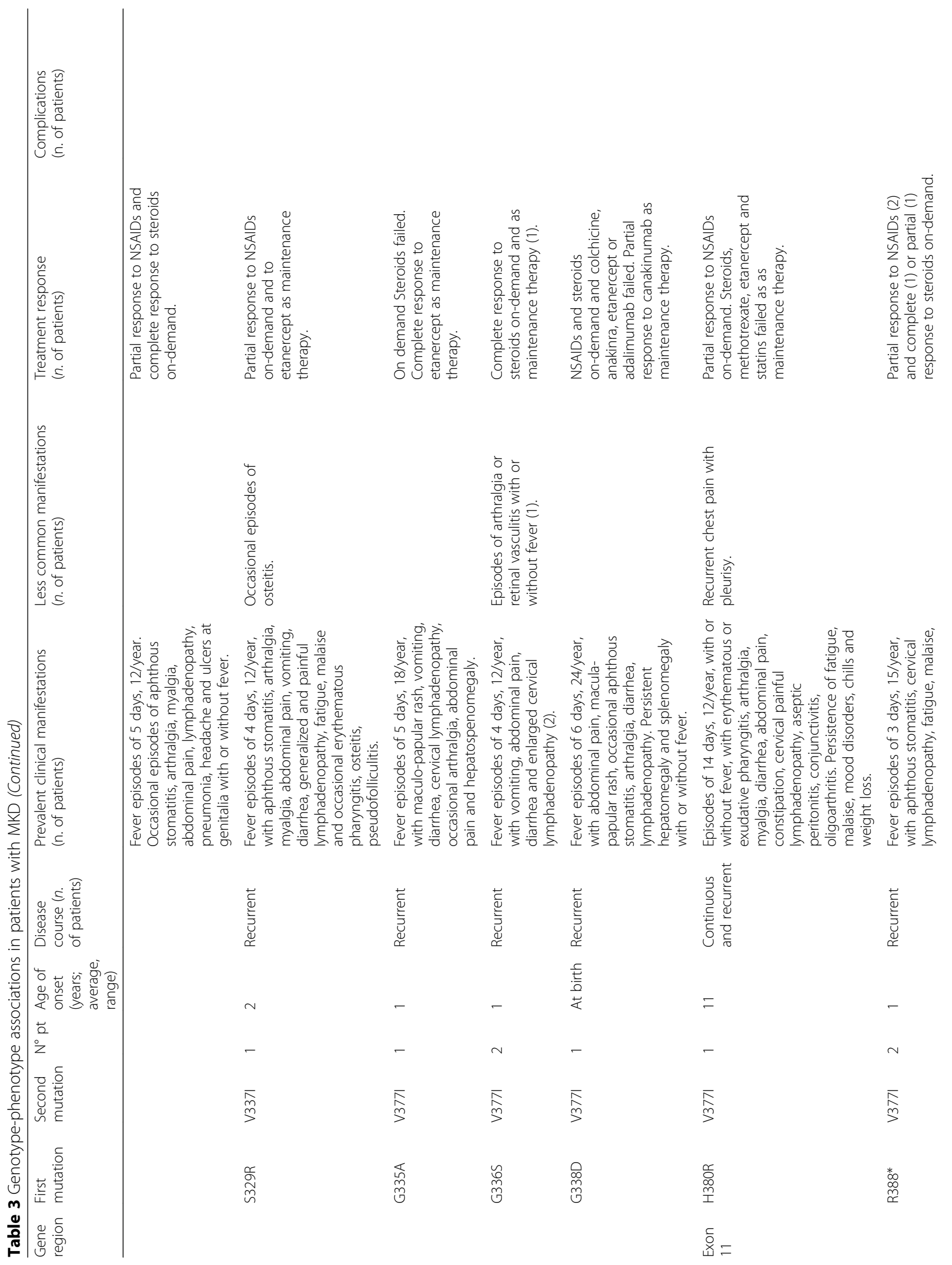




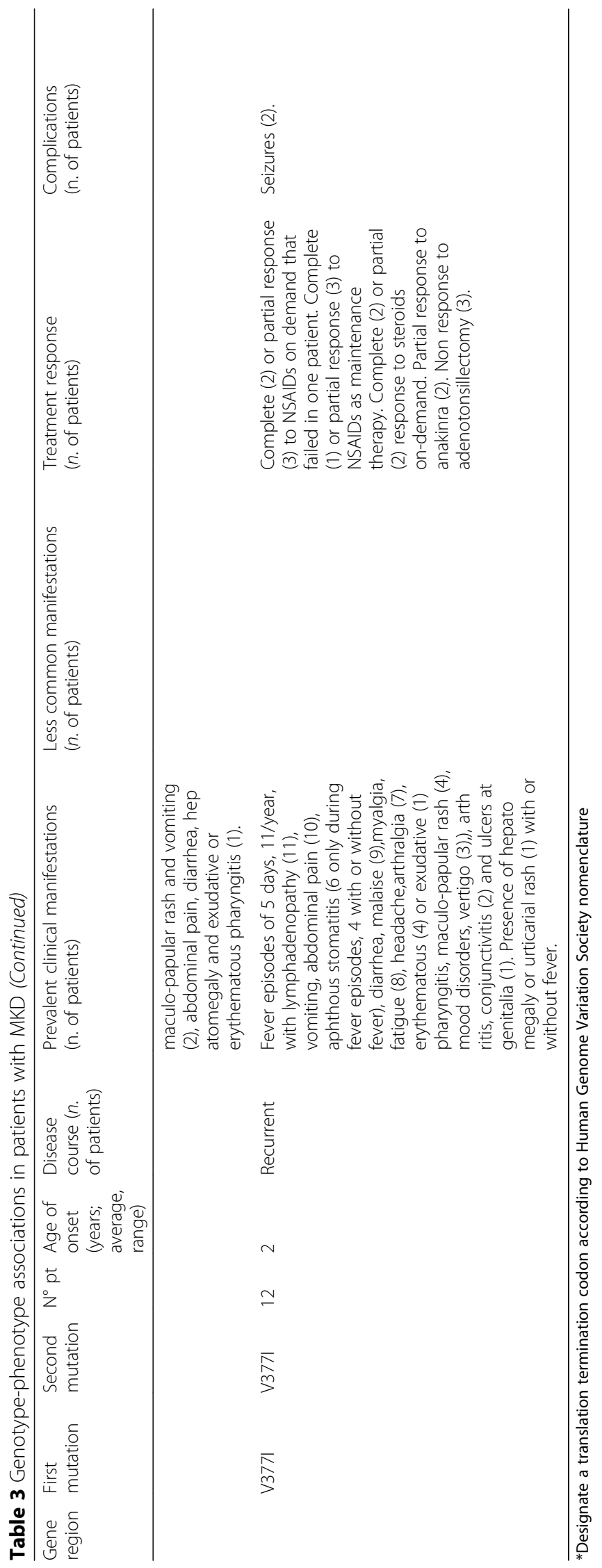




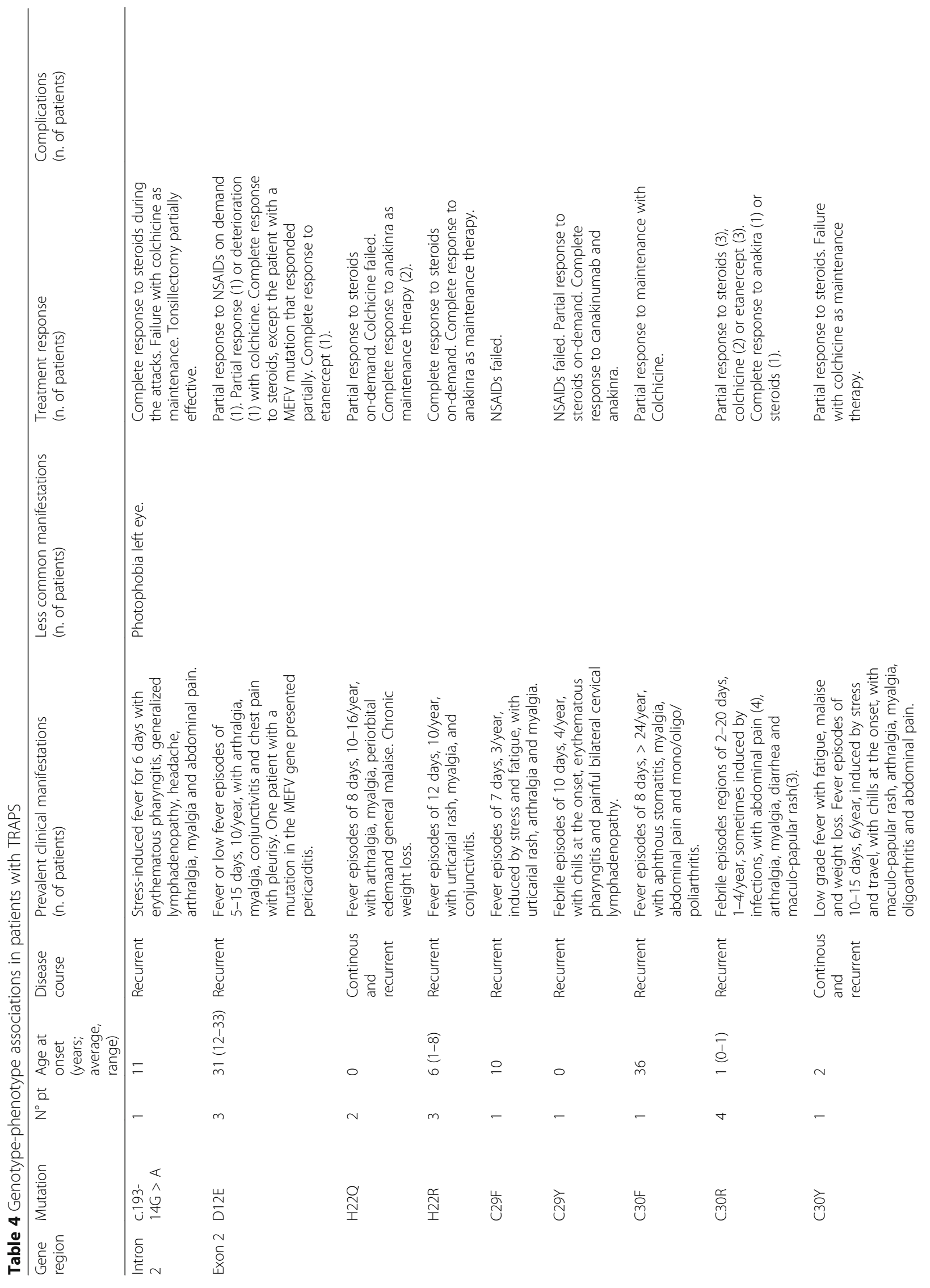




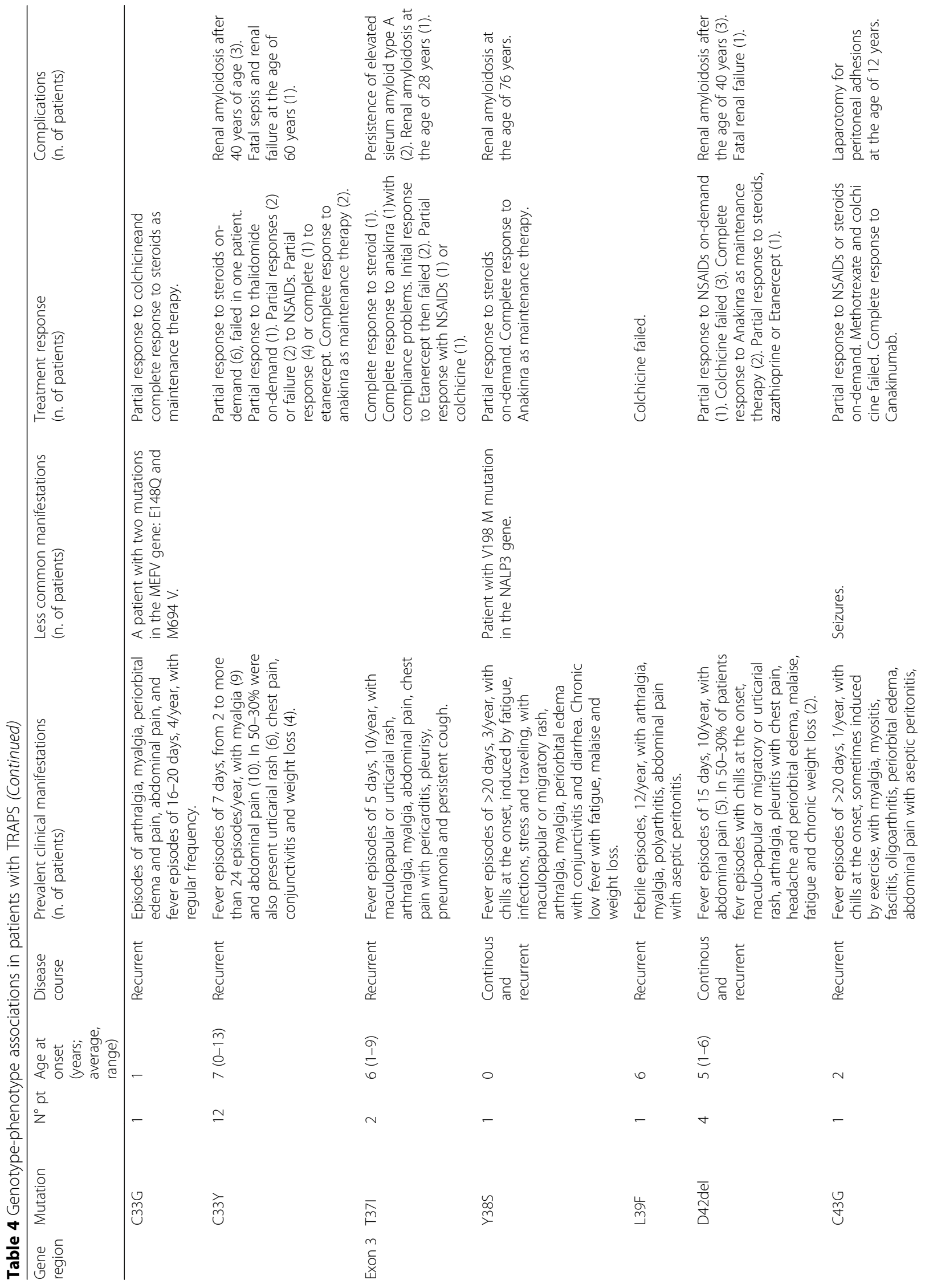




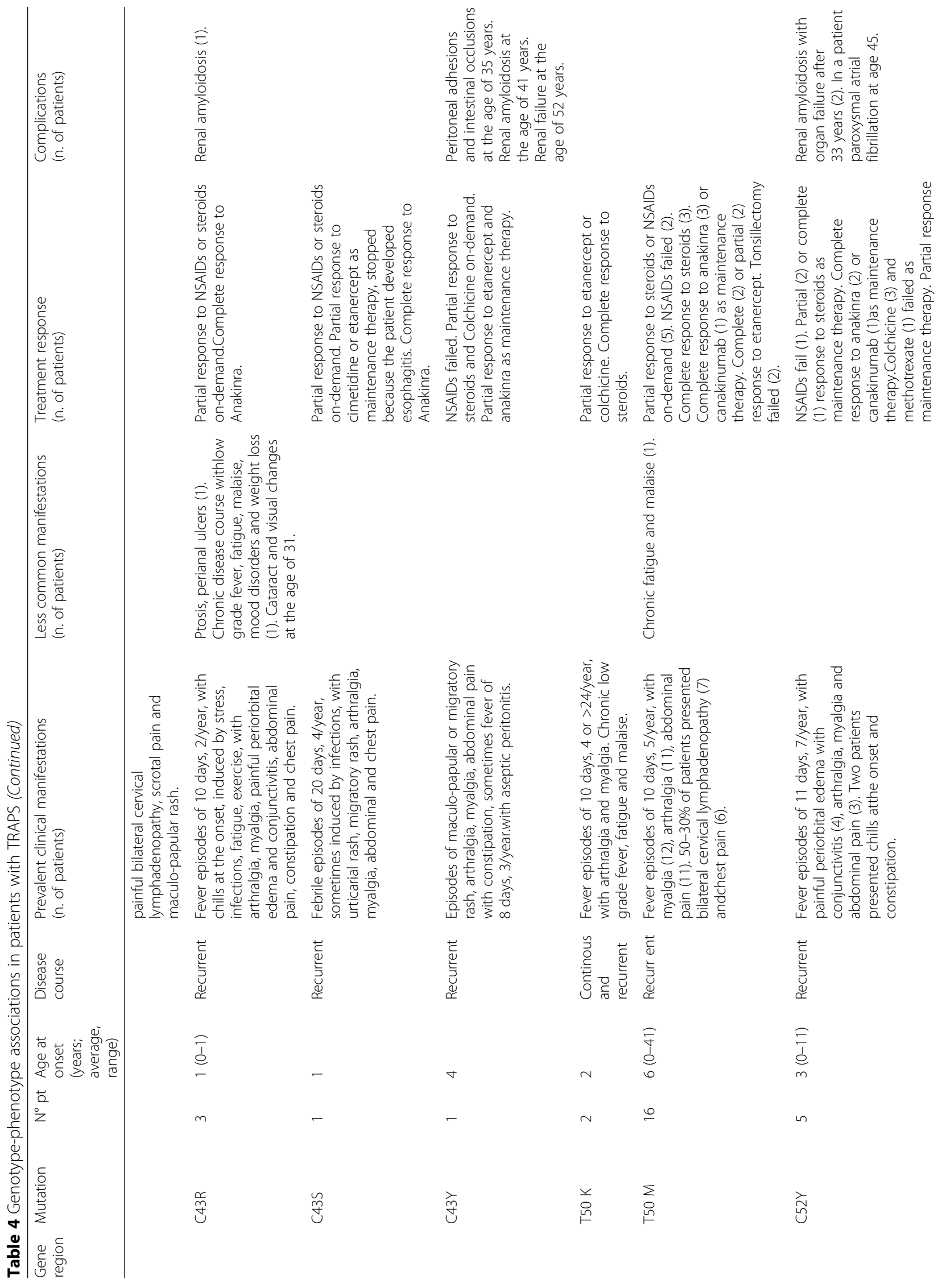




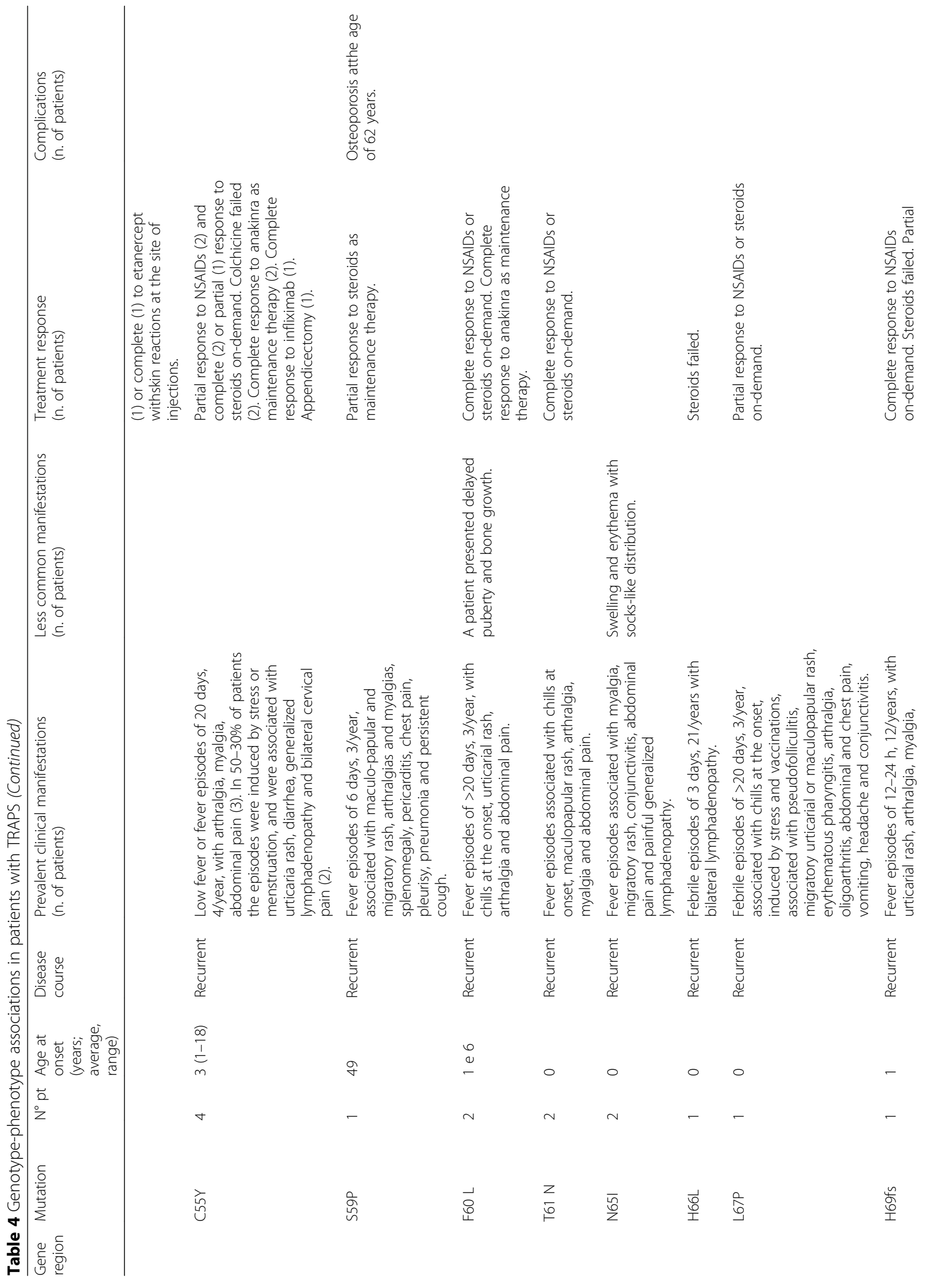




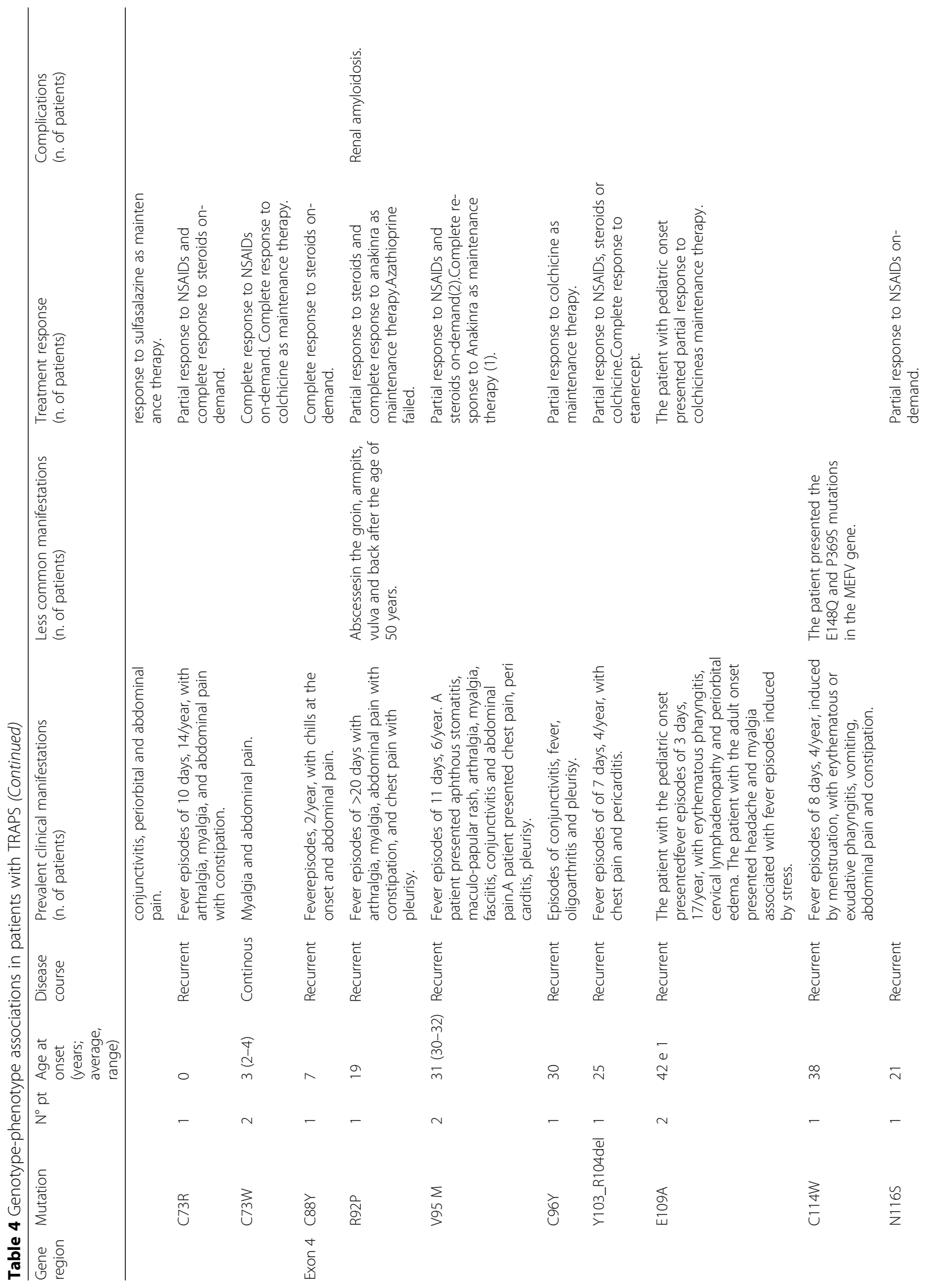




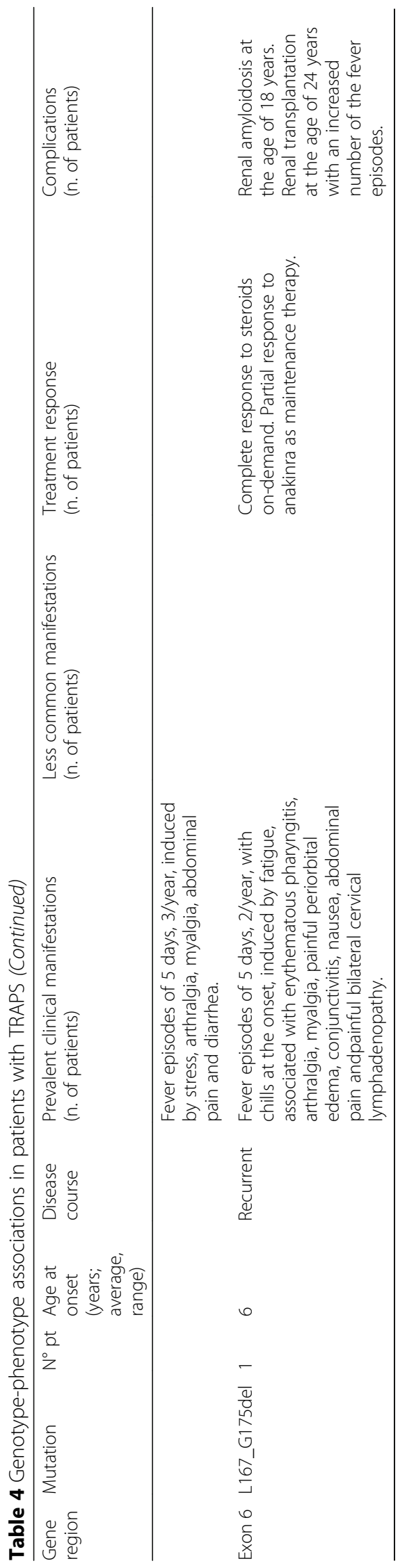




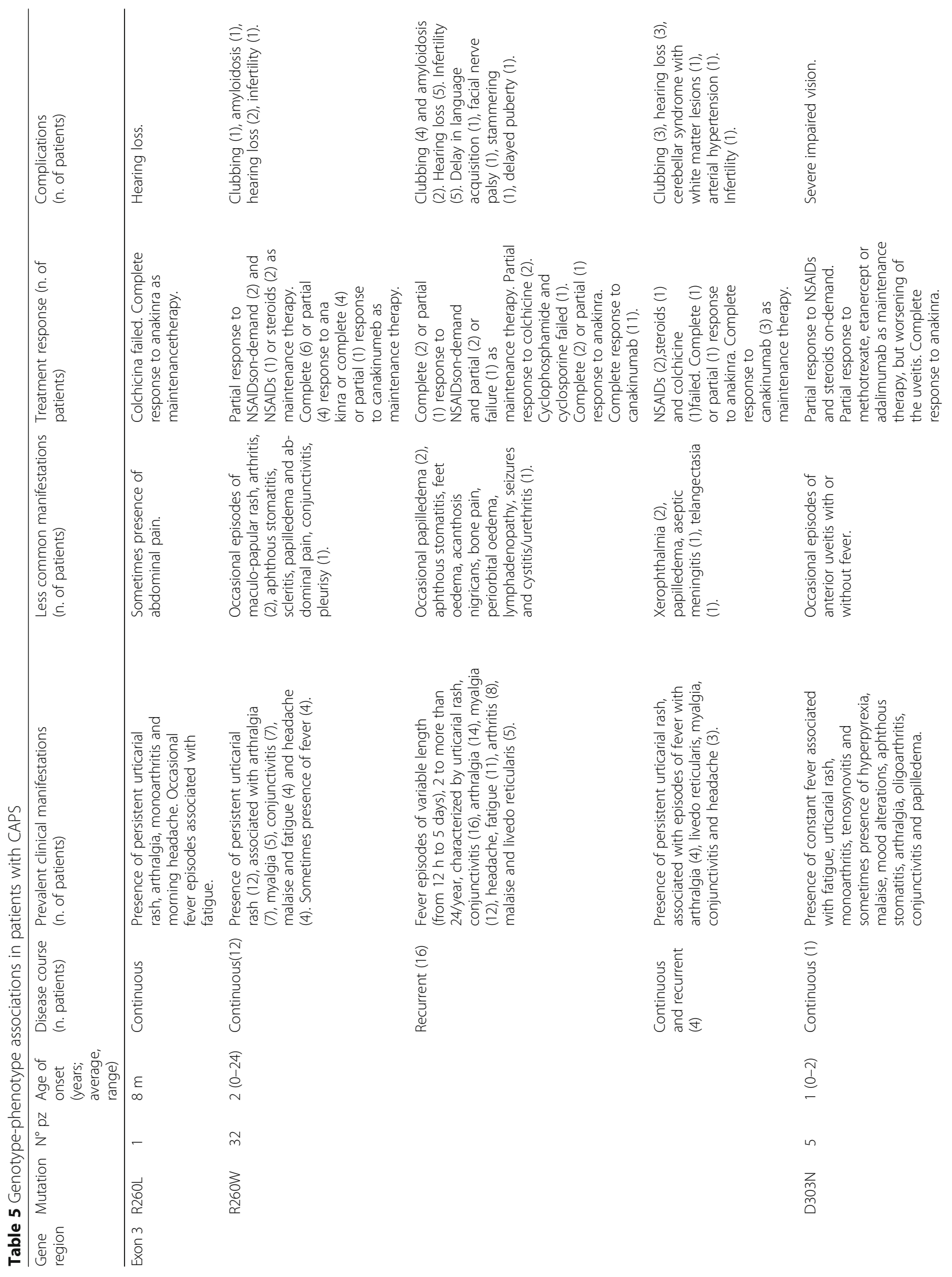




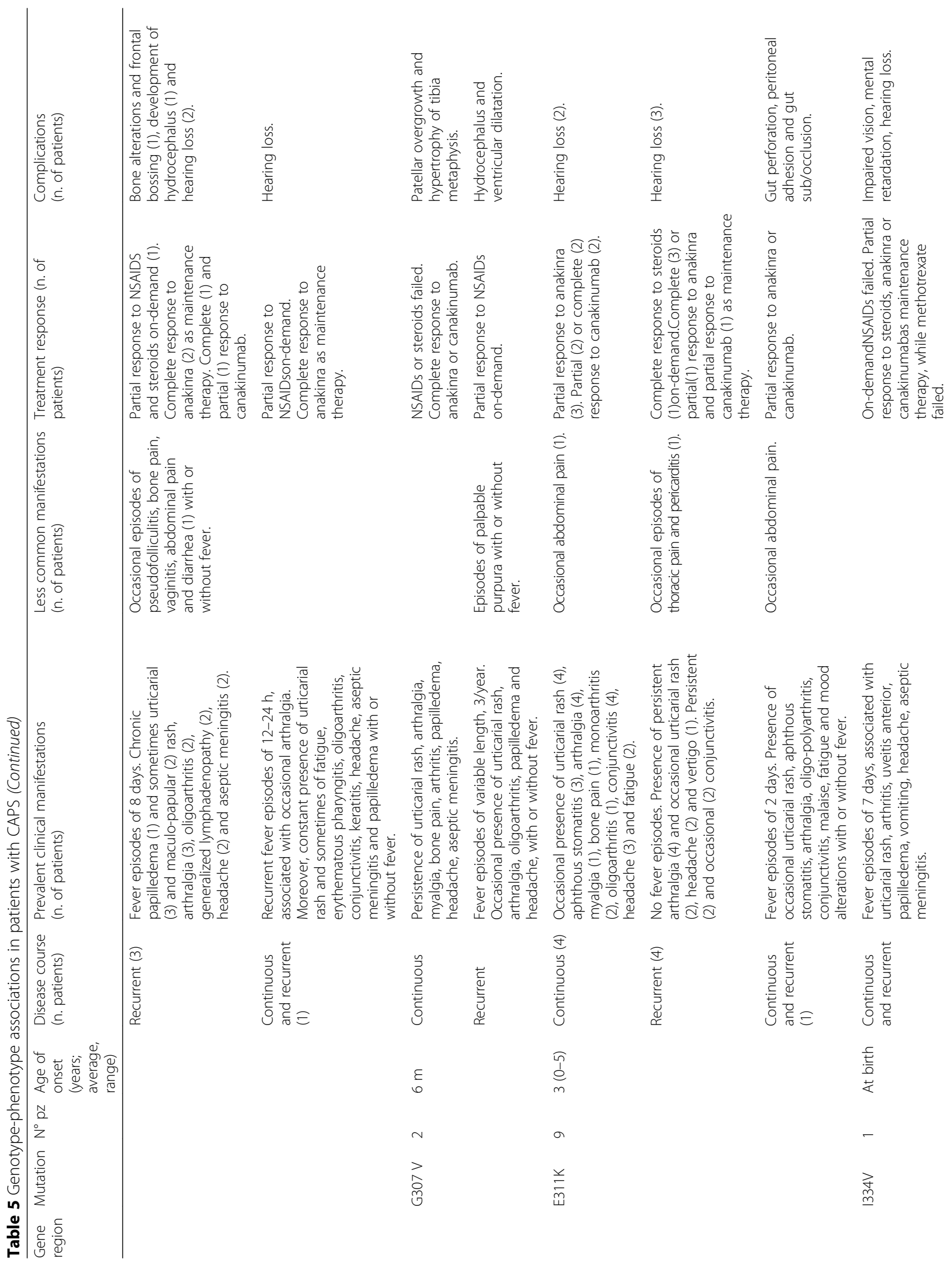




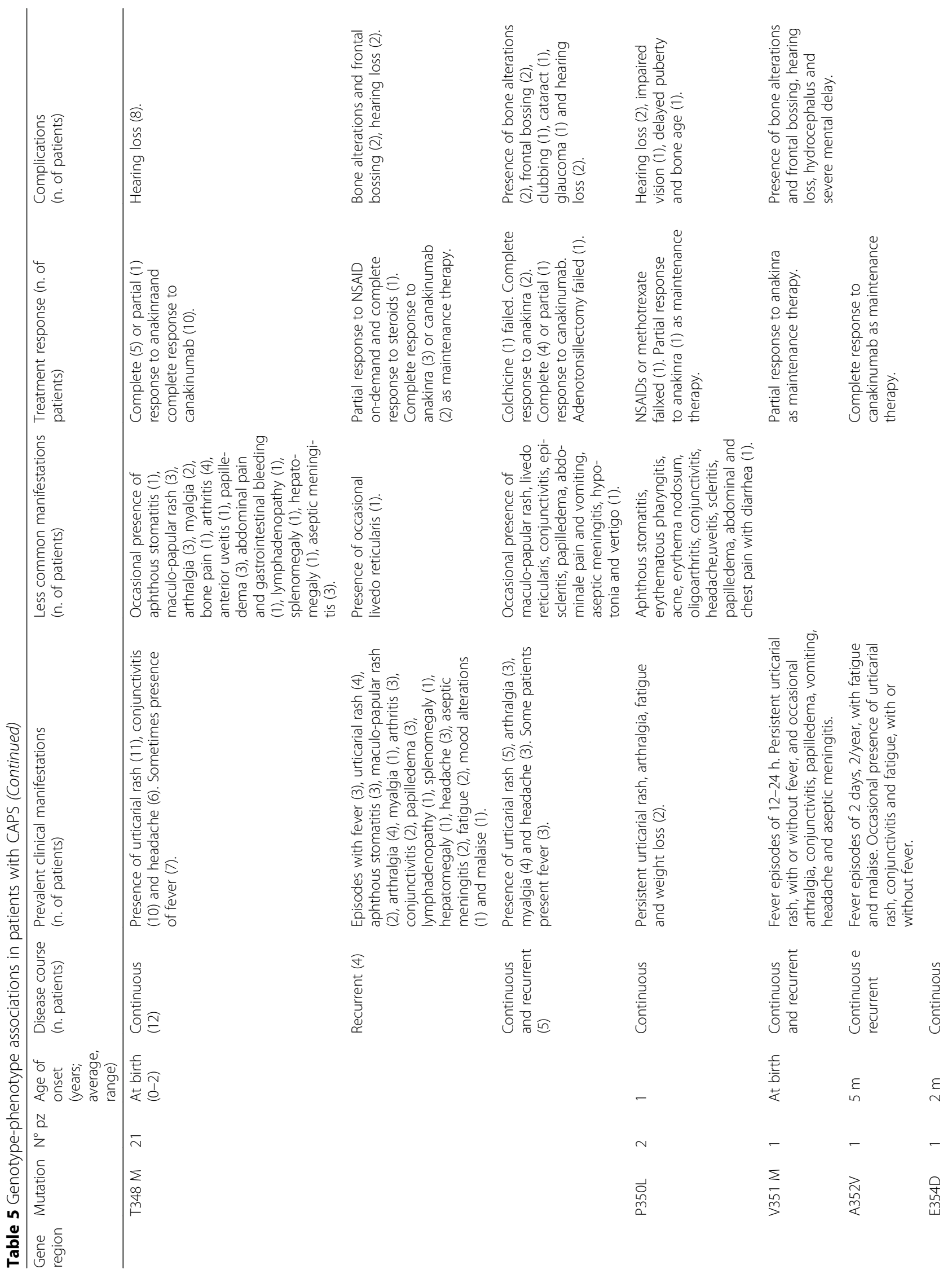




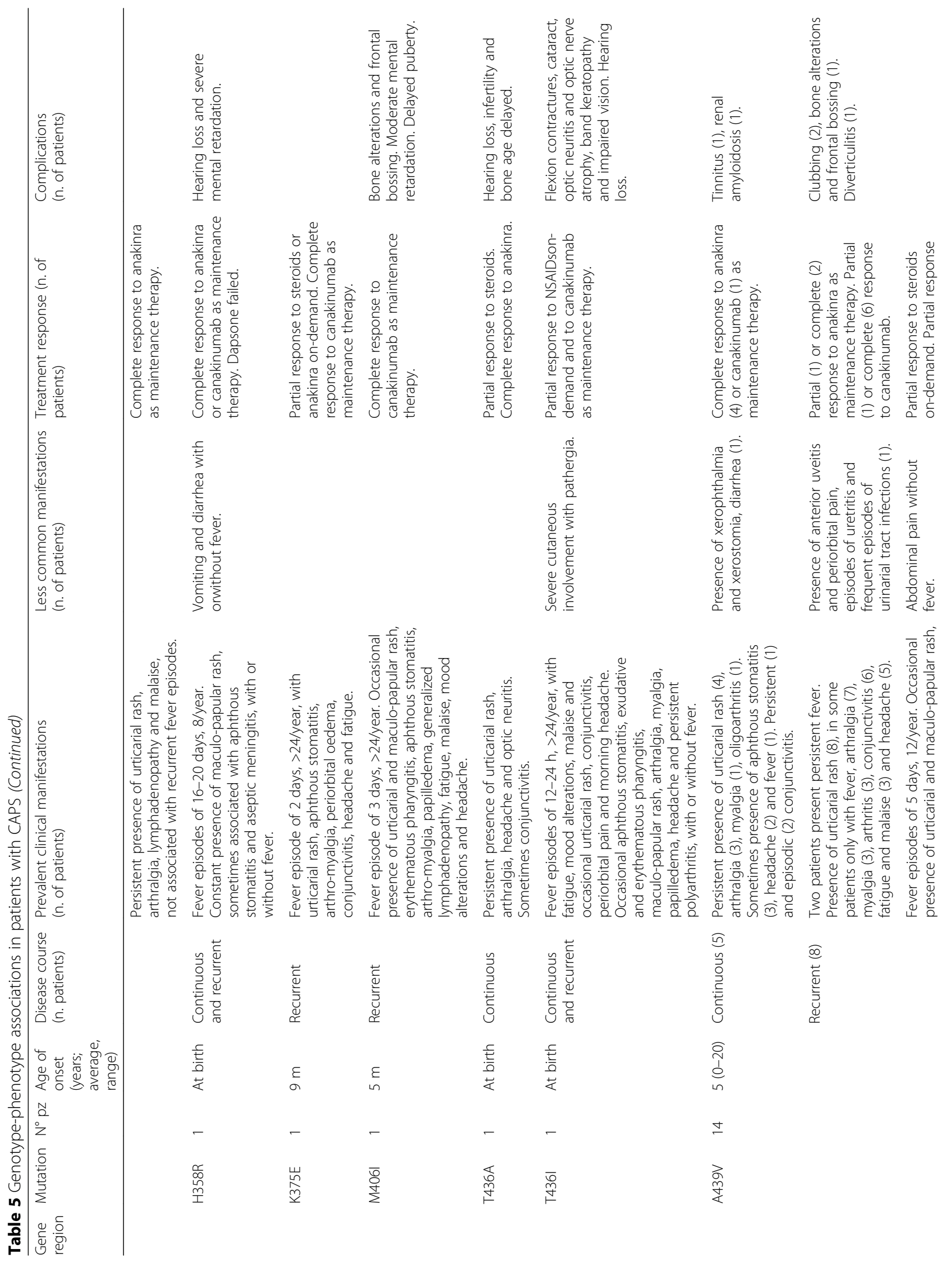




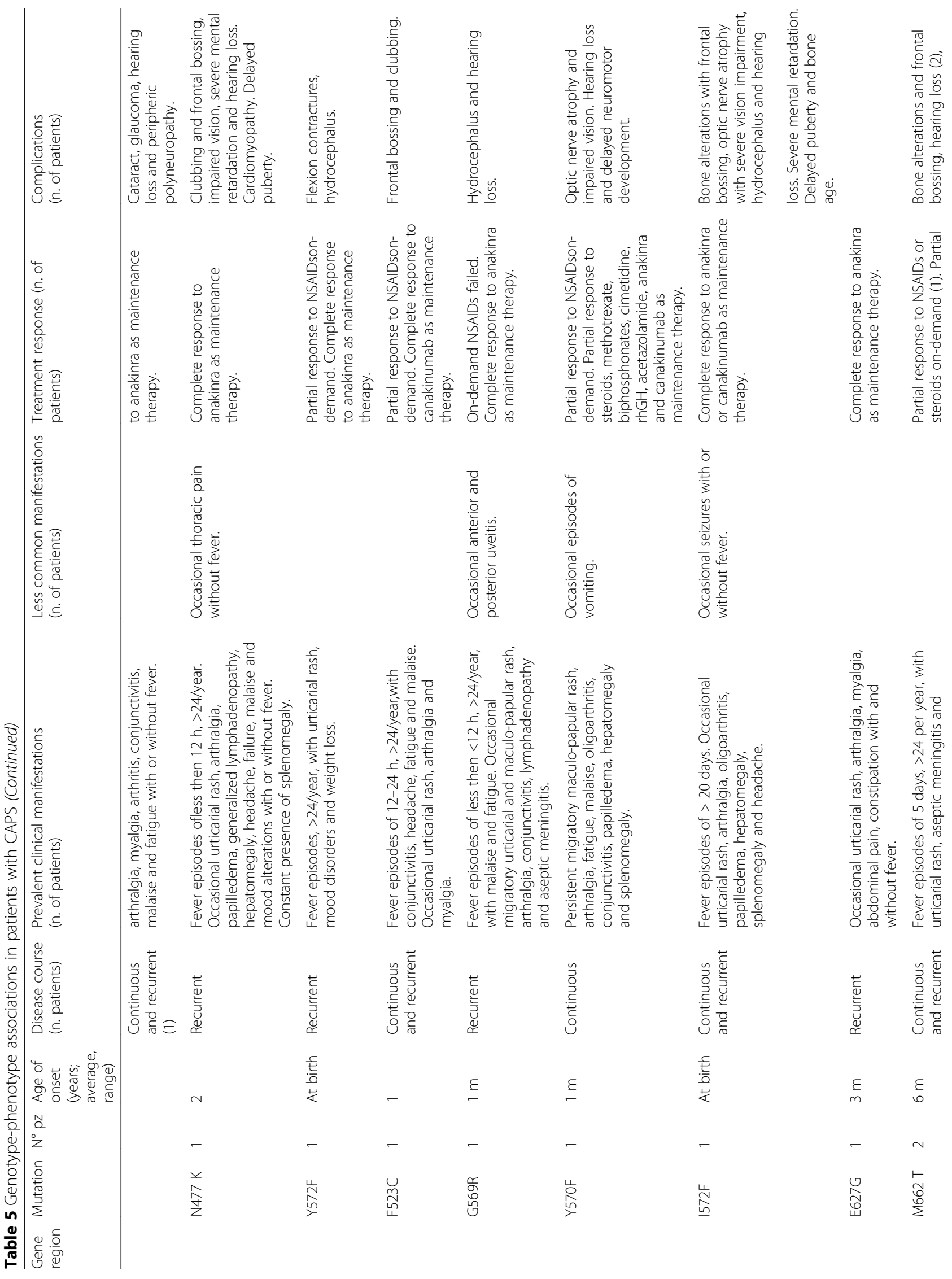




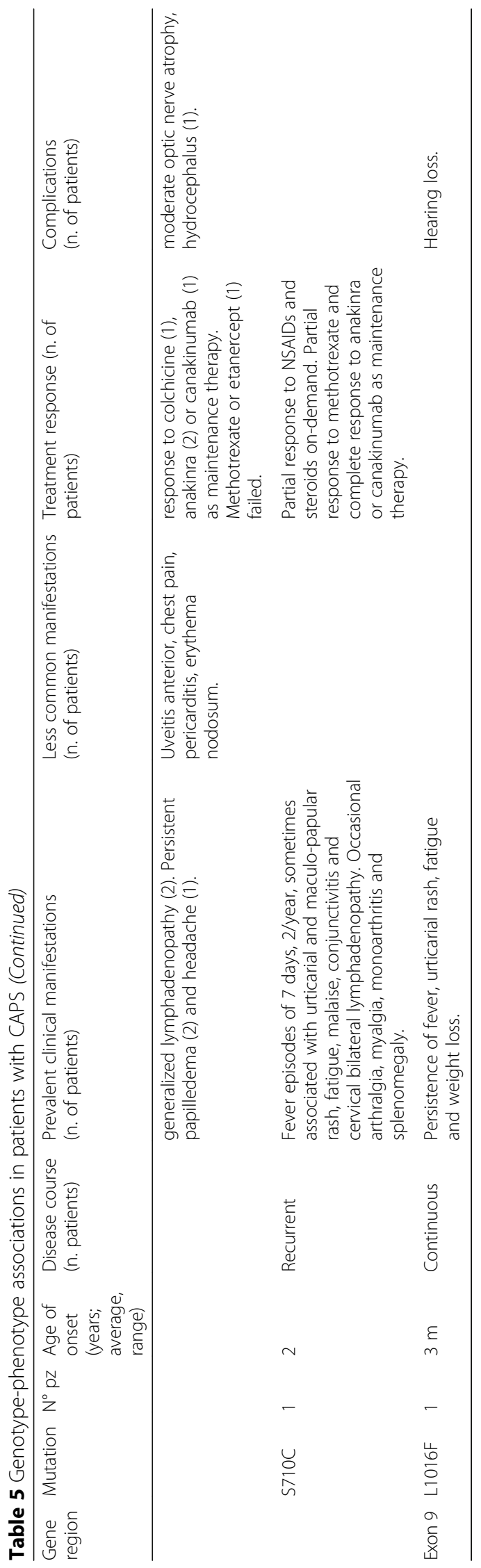




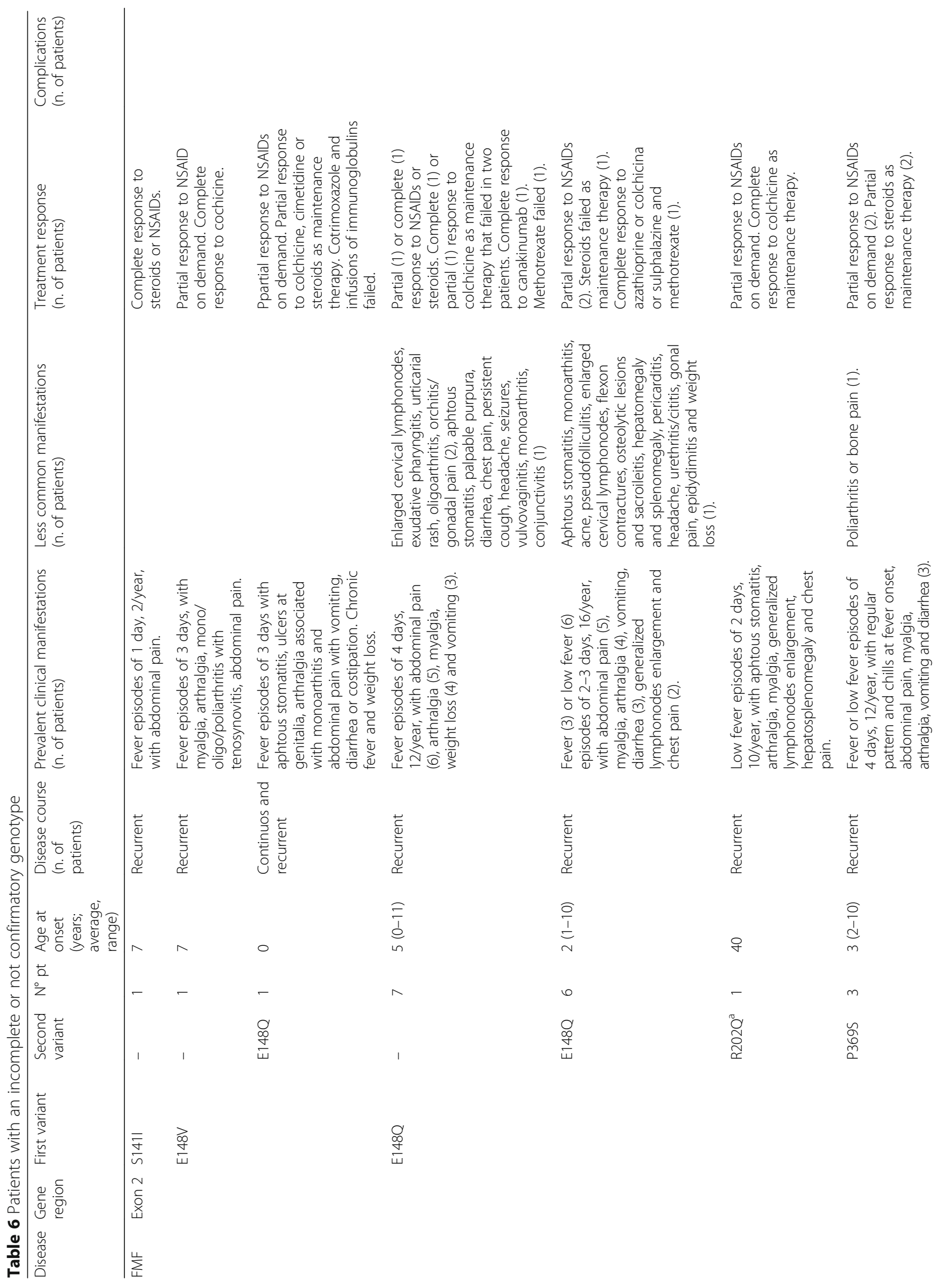




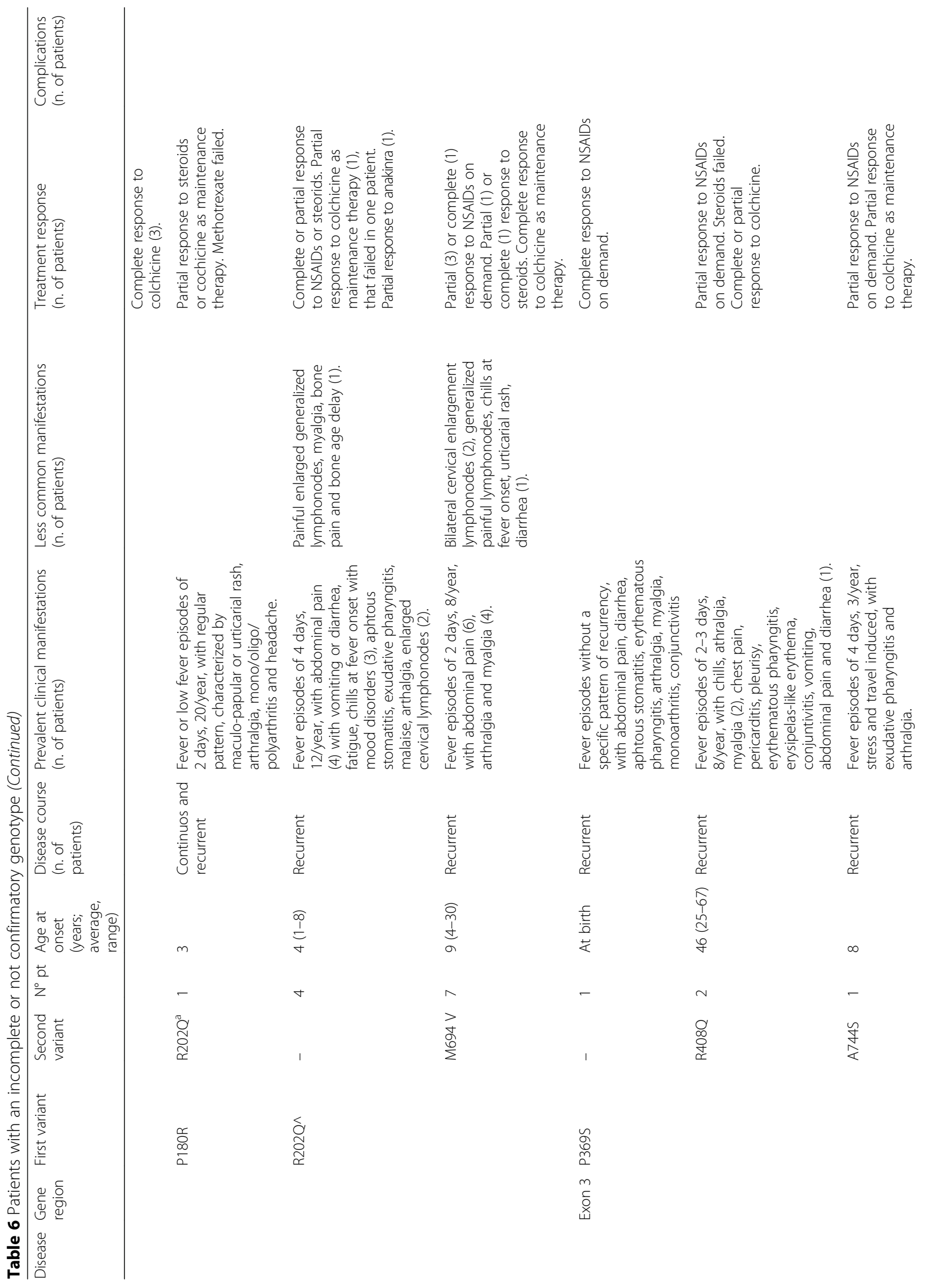




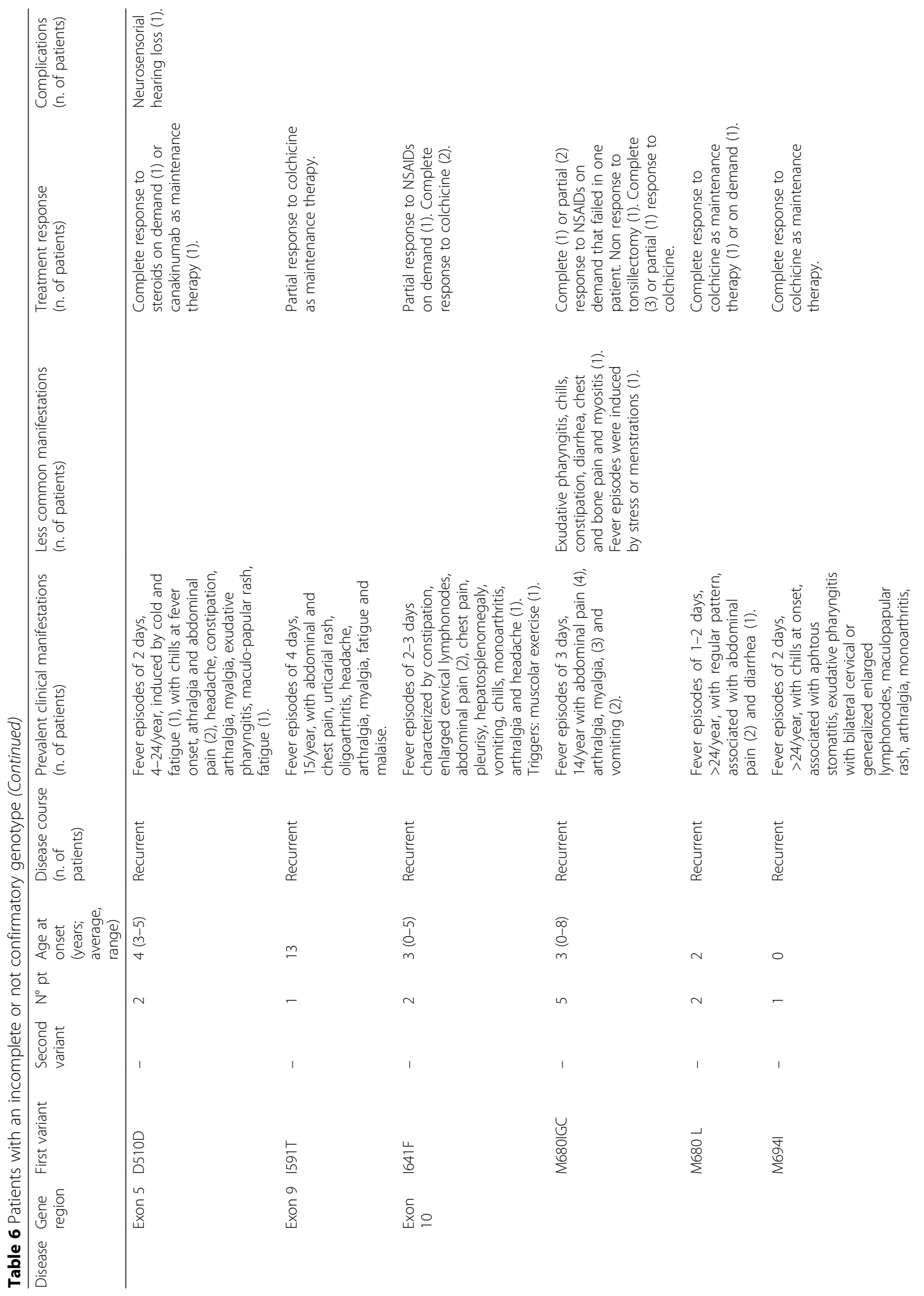




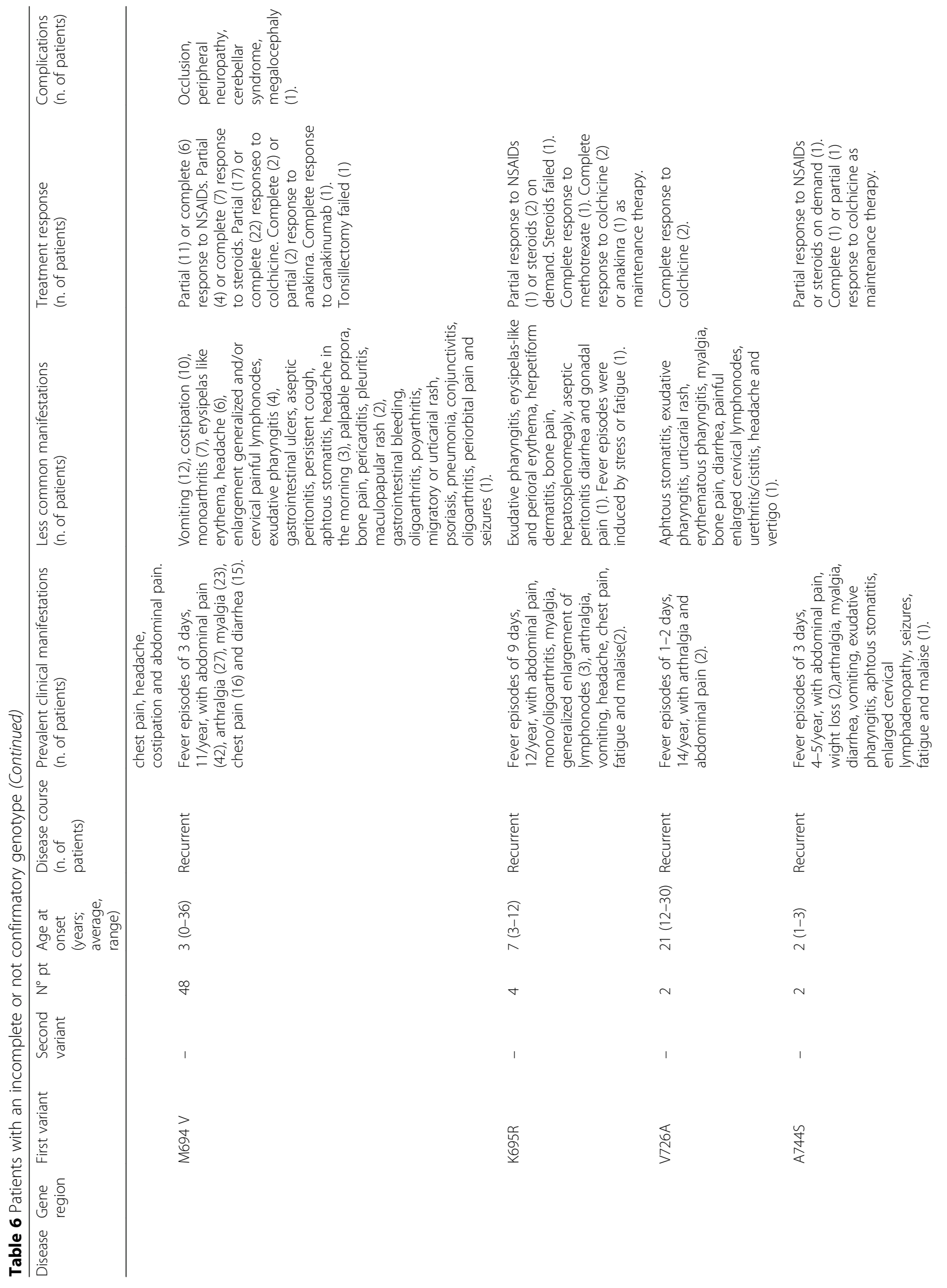




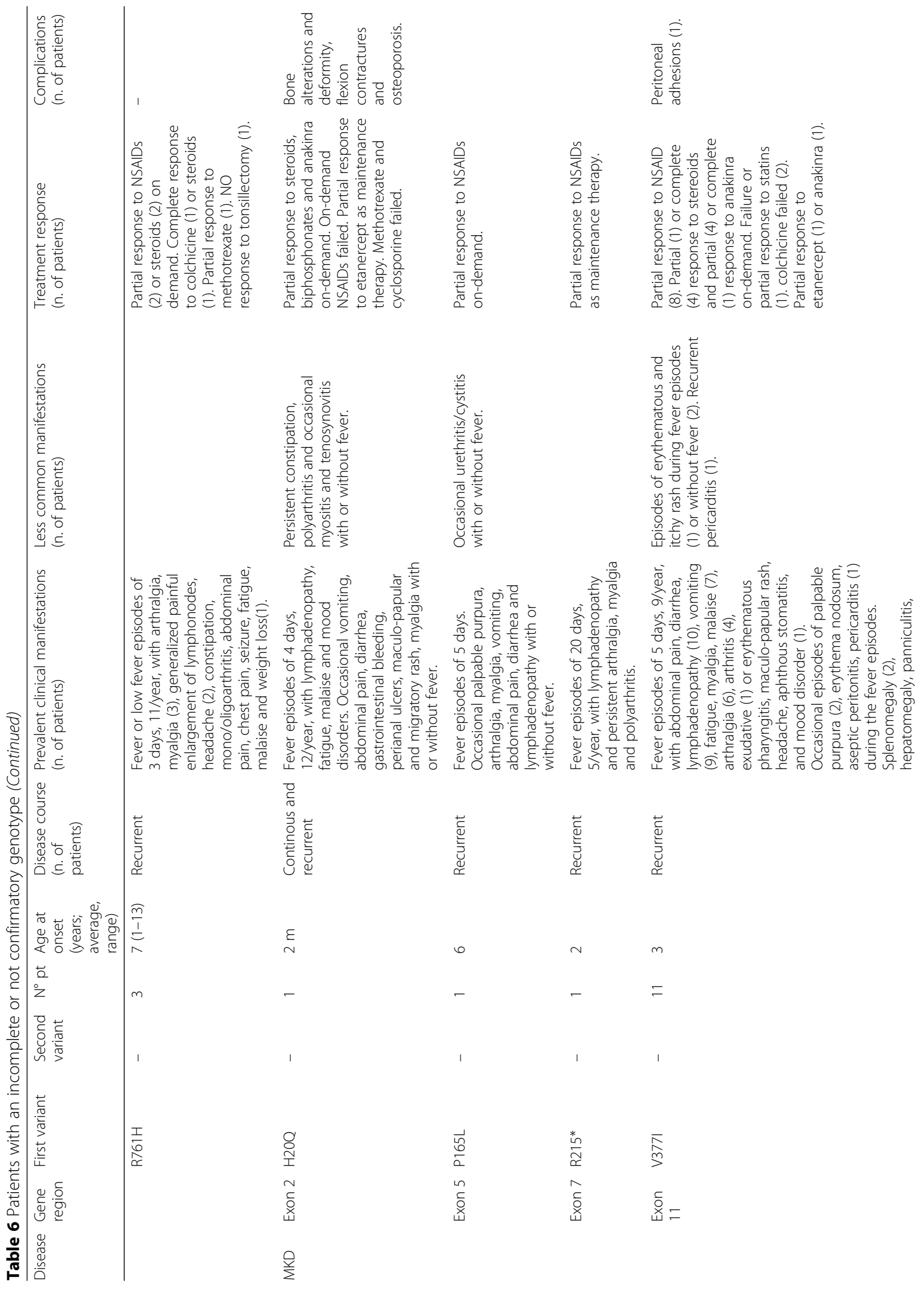




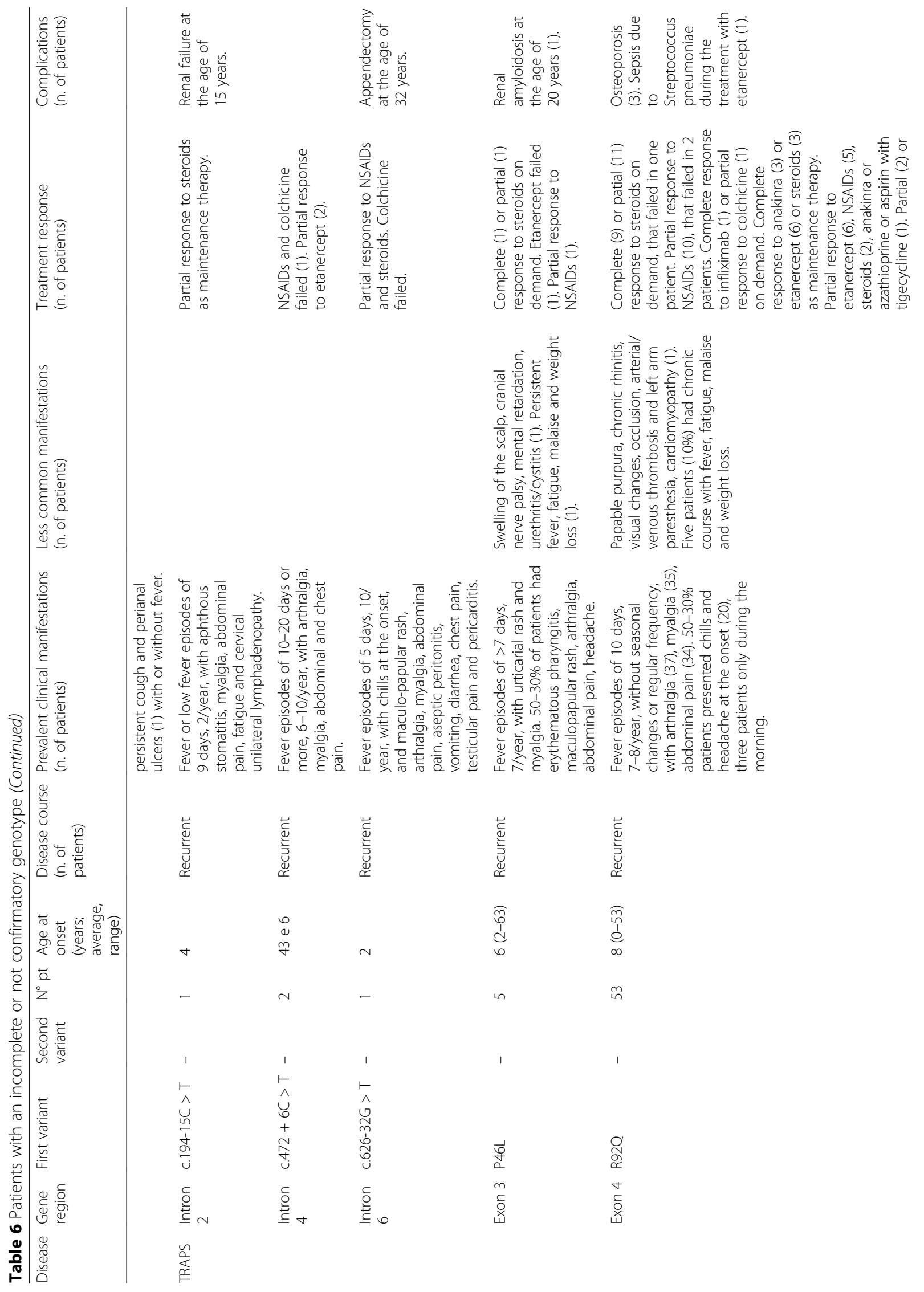




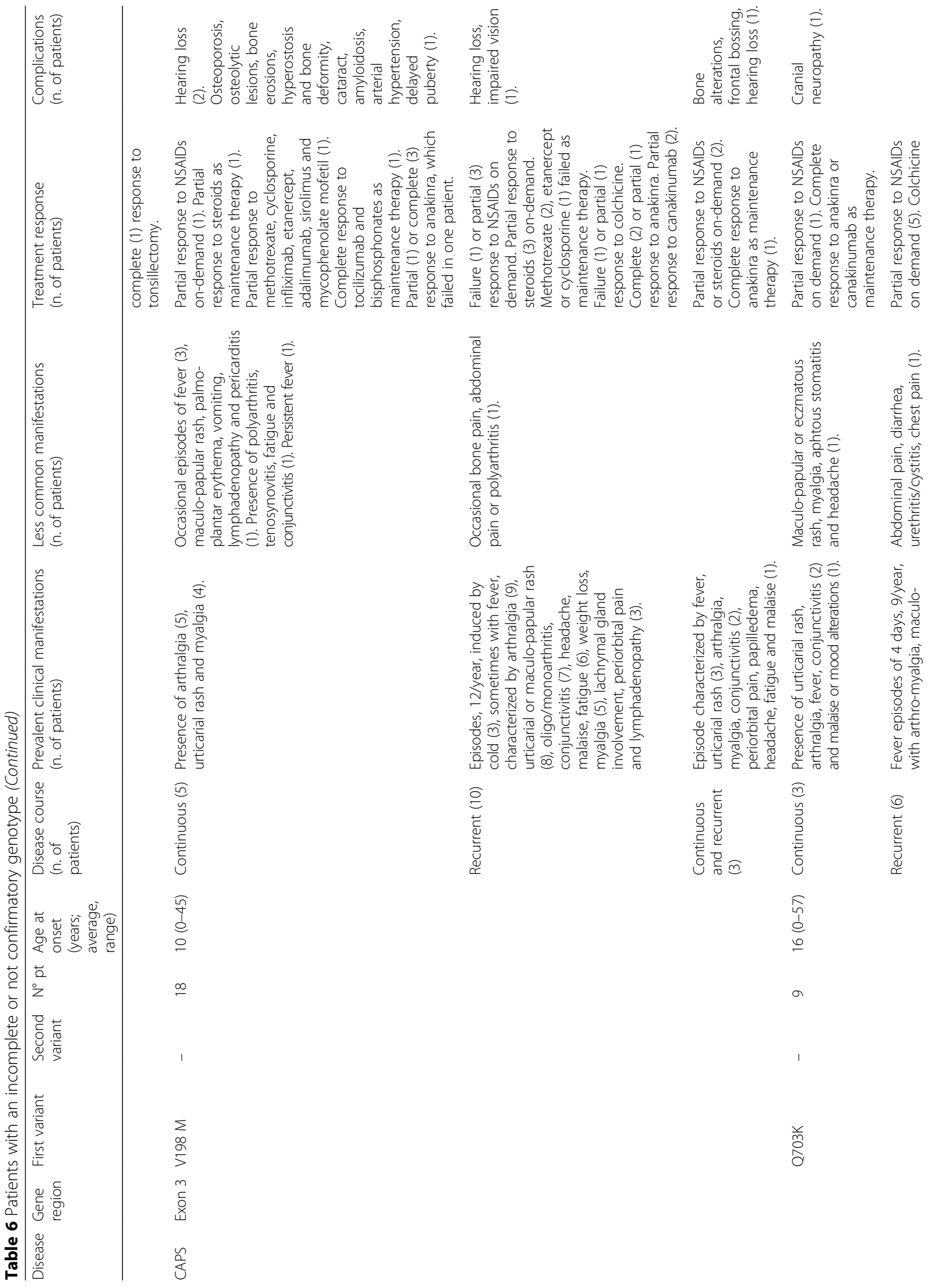




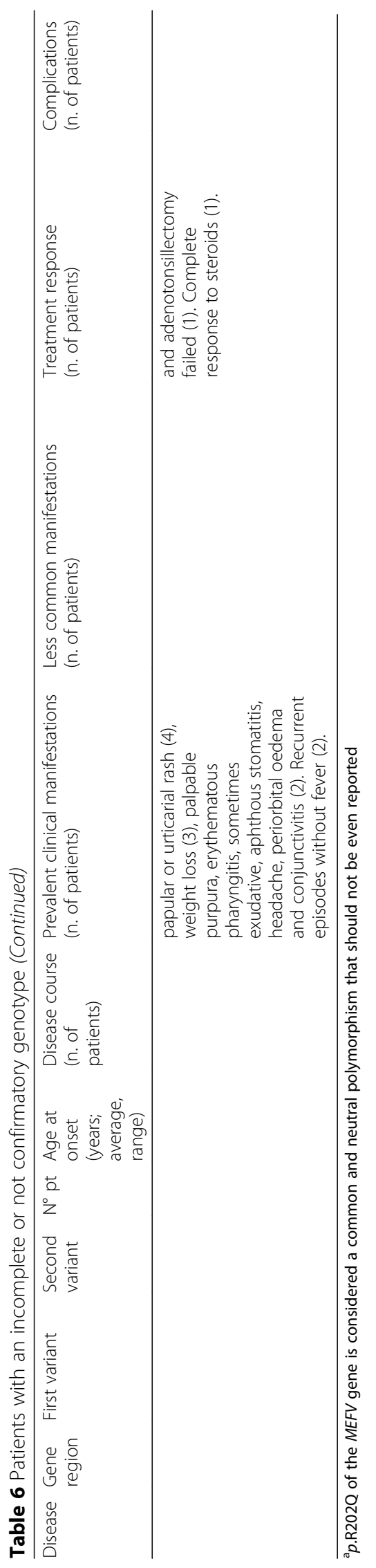


investigation of systemic inflammatory symptoms. As these patients enrolled into Eurofever represent only a minority of carriers of these genetics variants, the data presented should not be extrapolated to a decription of the phenotype in unselected patients who have undergone genetic testing. Moreover, it should be emphasized that only a limited proportion of the Eurofever patients carrying these low penetrance variants were selected in the process of validation, mainly because their clinical manifestations and response to treatment were consistent with the related disease.

The tables presented here will be available online, with links to the Eurofever (www.printo.it.eurofever) and Infevers websites. Moreover, a continuous updating of the tables will be performed for any new variant associated with patients enrolled in the Eurofever registry.

\section{Conclusions}

We provide a potentially useful tool for physicians dealing with HRF, namely a registry of genotype-phenotype associations for patients enrolled in the Eurofever registry. This tool is complementary to the Infevers database and will be available at the Eurofever and Infevers websites.

\section{Abbreviations}

CAPS: Cryopyrin-Associated Periodic Syndrome; FMF: Familiar Mediterranean Fever; HRF: Hereditary recurrent fevers; MKD: Mevalonate-Kinase Deficiency; TRAPS: TNF-receptor associated periodic fever syndrome

\section{Acknowledgements}

The Authors would like to thank Dr. E. Mosci and E. Patrone for their precious secretary assistance.

\section{Funding}

The Eurofever registry was sponsored by the Autoinflammatory Diseases' Working Group of the Paediatric Rheumatology European Society (PReS) and supported by the Executive Agency For Health and Consumers (EAHC, Project No 2007332). Novartis and SOBI have granted unrestricted educational grants.

\section{Availability of data and materials}

If you are not a member of the PRINTO network (www.printo.it) and wish to have more information on the Eurofever registry or other initiatives linked to the Eurofever Project, please write to marcogattorno@gaslini.org (Disease Pl: Marco Gattorno) or to printo@gaslini.org (Research Assistant: Eugenia Mosci).

\section{Authors' contributions}

RP, MD: participated in the design of the study, collected the data and drafted the manuscript. HJL, SO, JF, AS, BN, JKD, HO: participated in the design of the study, collected the data and helped to draft the manuscript. $R C, S F, M F, M T, J B, L B, M C P G, M C M, E T, W A S, G E, A S, G A$ : collected the data and helped to draft the manuscript. NR, AM, IC, MG: conceived of the study, and participated in its design and coordination and helped to draft the manuscript. All authors read and approved the final manuscript.

\section{Ethics approval and consent to participate}

Independent ethical approval for entering patients in the Eurofever registry and consent for partecipate was obtained in the participating countries, in accordance with local requirements.

\section{Consent for publication}

Independent consent for publication was obtained in the participating countries, in accordance with local requirements.

\section{Competing interests}

The authors declare that they have no competing interests.

\section{Publisher's Note}

Springer Nature remains neutral with regard to jurisdictional claims in published maps and institutional affiliations.

\section{Author details}

${ }^{1}$ EULAR Centre of Excellence in Rheumatology 2008-2018, IRCCS Istituto Giannina Gaslini, Genoa, Italy. ${ }^{2}$ National Amyloidosis Centre, Royal Free Campus, University College Division of Medicine, London, UK. ${ }^{3}$ Department of Pediatric Nephrology and Rheumatology, Hacettepe University, Ankara, Turkey. ${ }^{4}$ Division of Pediatrics, University Medical Center, Utrecht, The Netherlands. ${ }^{5}$ Department of Internal Medicine, Radboudumc Expertise Centre for Immunodeficiency and Autoinflammation, Radboudumc, Nijmegen, The Netherlands. ${ }^{6}$ Centre de reference national pour les Arthrites Juveniles, Unite d'Immunologie, Hematologie et Rhumatologie Pediatrique, Universite Paris-Descartes, IMAGINE Institute, Hopital Necker-Enfants Malades, Paris, France. ${ }^{7}$ Rheumatologisches Zentrum/Ambulanzfur Autoimmunerkrankungen, Universitatsklinikum Tubingen, Tubingen, Germany. ${ }^{8}$ IC Hastalıkları ABD, Romatoloji BD, Istanbul Universitesi Cerrahpaşa Tıp Fakültesi, Istanbul, Turkey. ${ }^{9}$ Department of Pediatrics I, Aristotle University of Thessaloniki, Thessaloniki, Greece. ${ }^{10}$ Department fur Kinder-und Jugendheilkunde, Klinikfur Padiatrie I, Padiatrische Rheumatologie, Medizinische Universität Innsbruck, Innsbruck, Austria. ${ }^{11}$ Immunology Unit, Hospital de Ninos Ricardo Gutierrez, Buenos Aires, Argentina. ${ }^{12}$ Unidad de Reumatología Pediátrica, Hospital Universitario Cruces, Bilbao, Spain.

${ }^{13}$ Dipartimento Universitario, Ospedale dei Bambini, Palermo, Italy. ${ }^{14}$ Pediatric Rheumatology Unit, 1st Department of Pediatrics, Children's Hospital Aghia Sophia, University of Athens, Athens, Greece. ${ }^{15}$ Department of Pediatrics, King Abdulaziz Medical City, King Saud bin Abdulaziz University for Health Sciences, Riyadh, Kingdom of Saudi Arabia. ${ }^{16}$ Seccion Reumatologia, Hospital de Niños Ricardo Gutierrez, Buenos Aires, Argentina. ${ }^{17}$ Research Institute for Paediatric Hematology, Moscow, Russia. ${ }^{18}$ EgeUniversitesi Tıp Fakultesi, Pediatrik Romatoloji, Izmir, Turkey. ${ }^{19}$ Direzione Scientifica, IRCCS Istituto Giannina Gaslini, Genoa, Italy. ${ }^{20}$ UOC Medical Genetics, IRCCS Istituto Giannina Gaslini, Genoa, Italy.

Received: 4 August 2017 Accepted: 6 October 2017

Published online: 18 October 2017

\section{References}

1. Gattorno M, Caorsi R, Meini A, et al. Differentiating PFAPA syndrome from monogenic periodic fevers. Pediatr. 2009;124:e721-8.

2. Milhavet $F$, Cuisset $L$, Hoffman HM, et al. The infevers autoinflammatory mutation online registry: update with new genes and functions. Hum Mutat. 2008;29(6):803-8

3. Ozen S, Frenkel J, Ruperto N, Gattorno M. The Eurofever project: towards better care for autoinflammatory diseases. Eur J Pediatr. 2011;170:445-52.

4. Ozen S, Demirkaya E, Amaryan G, et al. Results from a multicentre international registry of familial Mediterranean fever: impact of environment on the expression of a monogenic disease in children. Ann Rheum Dis. 2014;73:662-7.

5. Lachmann HJ, Papa R, Minden K, et al. The phenotype of TNF-receptor associated autoinflammatory syndrome (TRAPS) at presentation: a series of 158 cases from the Eurofever/EUROTRAPS international registry. Ann Rheum Dis. 2014;73:2160-7.

6. Levy R, Gérard L, Kuemmerle-Deschner J, et al. Phenotypic and genotypic characteristics of cryopyrin-associated periodic syndrome: a series of 136 patients from the Eurofever registry. Ann Rheum Dis. 2015;74:2043-9.

7. Ter Haar NM, Jeyaratnam J, Lachmann HJ, et al. The phenotype and genotype of Mevalonate Kinase deficiency: a series of 114 cases from the Eurofever registry. Arthr Rheum. 2016;68:2795-805.

8. Tchernitchko DO. Gèrard-Blanluet M, Legendre M, etal. Intrafamilial segregation analysis of the p.E148Q MEFV allele in familial mediterranean fever. Ann Rheum Dis. 2006;65:1154-7.

9. Ryan JG, Masters SL, Booty MG, et al. Clinical features and functional significance of the P369S/R408Q variant in pyrin, the familial Mediterranean fever protein. Ann Rheum Dis. 2010;69:1360-3. 
10. Ravet N, Ruaghe S, Dodè C. Et al.Clinical significance of P46L and R92Q substitutions in the tumour necrosis factor superfamily $1 \mathrm{~A}$ gene. Ann Rheum Dis. 2006;65:1158-62.

11. Aksentijevich I, Galon J, Soares M, et al. The tumor-necrosis-factor receptorassociated periodic syndrome: new mutations in TNFRSF1A, ancestral origins, genotype-phenotype studies, and evidence for further genetic heterogeneity of periodic fevers. Am J Hum Genet. 2001;69:301-14.

12. Rieber N, Gavrilov A, Hofer L, et al. A functional inflammasome activation assay differentiates patients with pathogenic NLRP3 mutations and symptomatic patients with low penetrance variants. Clin Immunol. 2015;157:56-64.

13. Naselli A, Penco F, Cantarini L, et al. Clinical characteristics of patients carrying the Q703K variant of the NLRP3 gene: a 10-year multicentric national study. J Rheumatol. 2016;43:1093-100.

14. Shinar Y, Obici L, Aksentijevich I, et al. Guidelines for the genetic diagnosis of hereditary recurrent fevers. Ann Rheum Dis. 2012;71:1599-605.

15. Ammouri W, Cuisset L, Rouaghe $S$, et al. Diagnostic value of serum immunoglobulinaemia D level in patients with a clinical suspicion of hyper IgD syndrome. Rheumatol (Oxford). 2007;46:1597-600.

\section{Submit your next manuscript to BioMed Central} and we will help you at every step:

- We accept pre-submission inquiries

- Our selector tool helps you to find the most relevant journal

- We provide round the clock customer support

- Convenient online submission

- Thorough peer review

- Inclusion in PubMed and all major indexing services

- Maximum visibility for your research

Submit your manuscript at www.biomedcentral.com/submit 